\title{
Self-managed working time and employee effort: theory and evidence
}

\author{
Michael Beckmann $^{\mathrm{a}}$, Thomas Cornelissen ${ }^{\mathrm{b}}$, Matthias Kräkel ${ }^{\mathrm{c}}$ \\ ${ }^{a}$ University of Basel, Faculty of Business and Economics, Department of Human Resources and \\ Organisation, Peter Merian-Weg 6, CH-4002 Basel, Switzerland \\ Phone: +41 6120732 24, fax: +41 612072758 \\ E-mail: michael.beckmann@unibas.ch \\ ${ }^{\mathrm{b}}$ University of York, Department of Economics and Related Studies, Heslington, \\ York YO10 5DD, United Kingdom \\ Phone: +44 1904323799 \\ E-mail: thomas.cornelissen@york.ac.uk \\ ${ }^{c}$ University of Bonn, Department of Economics, Institute for Applied Microeconomics (IAME), \\ Adenauerallee 24-42, D-53113 Bonn, Germany \\ Phone: +49 22873 3914, fax : +49 228739211 \\ E-mail:m.kraekel@uni-bonn.de
}

\begin{abstract}
This paper theoretically and empirically examines the impact of self-managed working time (SMWT) on employee effort. As a policy of increased worker autonomy, SMWT can theoretically increase effort via intrinsic motivation and reciprocal behaviour, but it can also lead to a decrease of effort due to a loss of control. Based on German individual-level panel data, we find that SMWT employees exert higher effort levels than employees with fixed working hours. Even after accounting for observed and unobserved characteristics there remains a modest positive effect. This effect is largely driven by employees who are intrinsically motivated, suggesting that intrinsic motivation is complementary to SMWT. However, reciprocal work intensification does not seem to be an important channel of providing extra effort.
\end{abstract}

JEL Classification: J24; J81; M50

Keywords: Self-managed working time, worker autonomy, employee effort, reciprocity, intrinsic motivation, complementarity 


\section{Introduction}

According to the social psychology literature, delegating authority to workers benefits employers, because authorised workers are highly motivated by feeling committed to their employers, leading to intrinsic motivation (Deci and Ryan, 1985, 2000) and reciprocal behaviour (Blau, 1964; Homans, 1958). In other words, received autonomy is likely to interact with the two personality traits intrinsic motivation and reciprocity. Recent work in behavioural economic theory yields similar results (Delfgaauw and Dur, 2008; Dur et al., 2010). The economic literature, however, emphasises the following trade-off for employers when delegating authority to their workers (Aghion and Tirole, 1997; Aghion et al., 2013; Bloom and Van Reenen, 2011): On the one hand, increased motivation associated with higher worker authority may raise performance. On the other hand, workers can abuse their authority and this can reduce performance.

In our paper, we address this trade-off by focusing on one key component of delegated authority - workers' autonomy over their working time. In particular, we are interested in working time arrangements that allow workers to control the starting and finishing times of their workday, to set their breaks, vacation days and days off, and to freely distribute their workdays over the working week. Many of these regimes additionally include the decision right upon the place of work and thus allow working from home, at least occasionally (Kelly and Moen, 2007; Nijp et al., 2012; Shockley and Allen, 2012). We refer to such arrangements as self-managed working time (SMWT).

A natural consequence of SMWT is that employers no longer need to record actual working hours. While the omission of working hours registration enables the employer to save monitoring costs, it also harms his opportunities to control the workers' effort. This implies that the employer relies on his workers to abstain from exploiting their time sovereignty opportunistically by reducing effort. ${ }^{1}$ SMWT is a widespread phenomenon. In the United States about $15 \%$ of employees are able to completely determine working hours on their own (Golden, 2012), while the corresponding percentage is about 17\% for EU27 employees (Goudswaard et al., 2012). Yet, a theoretical analysis of SMWT does not exist and empirical evidence on the effects of this type

\footnotetext{
${ }^{1}$ Probably, this is why SMWT is sometimes also called trust-based working time (e.g., Singe and Croucher, 2003; Godart et al., 2016). Other expressions used in the literature include work time control, schedule control, trust hours, or boundary-less work (Beckers et al., 2012; Kelly and Moen, 2007).
} 
of autonomy on worker performance is still scarce. As we document below, existing studies in this area typically analyse particular firms or occupations, or provide experimental evidence.

In the present paper, we study the effect of working time autonomy on worker performance in a closely linked theoretical and empirical analysis. We also analyse how a worker's personality interacts with SMWT, focussing on two personality traits that boost individual performance according to social psychology. In the theoretical analysis, we develop a modified moral-hazard model, which includes intrinsic motivation, reciprocal behaviour, and endogenous monitoring precision that depends on the chosen working time arrangement. The key contribution of the model is to analyse how working time autonomy interacts with the two personality traits, and to derive testable empirical implications. While there is qualitative and case-study evidence suggesting that personality traits moderate employee responses to working time arrangements (e.g., Kelliher and Anderson, 2010; Lambert, 2000), a rigorous theoretical analysis of how the interaction of personality traits and working time autonomy affects performance has not yet been provided in the literature. Our theoretical model shows that the impact of working time autonomy on worker performance is ambiguous. On the one hand, due to high working time autonomy and low monitoring precision, the employer prefers low-powered extrinsic incentives. Consequently, workers choose low effort under the optimal incentive scheme. On the other hand, additional intrinsic motivation and incentives from reciprocating received autonomy can provide extra effort, so that the overall impact of working time autonomy on effort depends on which effect dominates.

Our empirical analysis tests which of the two theoretical effects is stronger in practice. It draws on one of the most extensive household survey panel datasets in Europe, the German Socio-Economic Panel (SOEP), which includes information on individual workers and on the firms in which they are employed. Our empirical findings imply that SMWT has a moderate, positive net effect on worker effort, a result which is very robust across a range of alternative performance measures and across various specifications, including an instrumental variables approach. In addition, we find that this positive effort effect is largely driven by increased intrinsic worker motivation, whereas reciprocity does not seem to be an important factor.

There are several advantages of using the SOEP. First, the representativeness of the data set allows us to draw more generalizable conclusions than parts of the existing literature that have 
looked at non-random or selected samples. Second, the panel character of the data improves upon the vast majority of the empirical literature in this field that is based on cross-sectional data. This allows us to address potential endogeneity problems and thus to derive managerial implications with regard to an effective use of SMWT. Third, although measures of effort or performance at work are usually difficult to find in individual survey data spanning a range of different occupations and firms, the SOEP offers several alternatives. Our main measure for worker effort is the difference between actual and contractual working hours to which we also refer as extra working time. We believe that this is a legitimate measure of worker effort, because spending time at work is clearly costly to the worker in terms of opportunity cost, and more time spent at work is likely to increase the worker's output (e.g., Bell and Freeman, 2001). But we also use alternative proxies for performance, such as hourly wages and absenteeism from work.

Our empirical approach addresses several endogeneity problems. Suppose that more (or less) motivated employees select into workplaces or jobs with SMWT, or that firms that require higher effort from their employees (or that offer more incentives for effort) are more likely to operate SMWT. This would lead to a spurious non-causal association between SMWT and worker performance. We deal with this by including worker-firm spell fixed effects. This implies that the variation we exploit results from changes in SMWT that workers experience while being employed in the same firm, thus holding time-invariant unobserved worker and firm characteristics constant. A remaining threat to identifying a causal effect occurs if firms that introduce SMWT change other aspects of the job that may affect worker performance, such as performance monitoring, autonomy in carrying out tasks, task content, or aspects of the work contract. We deal with such concerns by controlling for the degree of performance monitoring, overall job autonomy, a large set of narrowly defined 4-digit occupation dummies, job satisfaction and aspects of the work contract such as full-time status, contractual working time and fixed-term employment. Moreover, in order to account for any potentially remaining timevarying unobserved heterogeneity, we also report results from an instrumental variables estimation strategy. Finally, we explore the heterogeneity of the SMWT effect using a quantile regression approach.

Our theoretical approach is related to the growing field of behavioural economics. The model used in this paper integrates the problem of hidden costs of control as introduced by the 
seminal paper of Falk and Kosfeld (2006). By using a laboratory experiment, they show that agents will choose lower performance if the principal limits their discretion by imposing a minimum performance standard. In that case, the agents feel distrusted by the principal, which destroys part of their intrinsic motivation. Falk and Kosfeld mention different possibilities for a minimum performance standard, in particular "a minimum presence requirement" (p. 1611), which would violate strong forms of SMWT like working from home. Ellingsen and Johannesson (2008) consider a behavioural economic model that can explain the findings of Falk and Kosfeld. In their setting, forgoing control can signal a prosocial attitude of the principal, which leads to higher motivation of the agent if being of a prosocial type. Benabou and Tirole (2006) develop another theory of prosocial behaviour, which includes intrinsic motivation, being also important for our model. Our theoretical approach is most closely related to Delfgaauw and Dur (2008) by modelling intrinsic motivation and to Dur et al. (2010) by modelling reciprocity.

Our paper contributes to the existing empirical literature on the effect of working time autonomy on individual performance. Using data from seven biopharmaceutical firms in one US state, Eaton (2003) finds that employee control over time, pace and place of work has a positive impact on perceived productivity and organisational commitment. Analysing one cross-section of international survey data, Lyness et al. (2012) find that worker control over working time has a positive association with organisational commitment and job satisfaction. In a largely qualitative study covering workers from three private sector organisations in the UK, Kelliher and Anderson (2010) additionally find evidence for increased work intensification and conclude that employees reciprocate when given the opportunity to work flexibly by exerting additional effort. Based on personnel records of call centre employees from a large Chinese multinational firm, Bloom et al. (2015) conduct an intervention study on the effects of work from home (as an element of worker autonomy) on individual performance. Apart from a 13\% productivity increase, the authors find an additional performance effect caused by employee self-selection. Based on experimental evidence and distinguishing between dull and creative tasks, Dutcher (2012) draws mixed conclusions. The author finds that while the autonomy to work from home is associated with an 11-20\% productivity increase when workers deal with creative tasks, individual productivity declines by 6-10\% when workers deal with dull tasks. This mixed evidence is confirmed by the field- and laboratory-based analyses of Leslie et al. (2012) who find that the effect of flexible work practices (including control over time and place of work) on a 
worker's career depends on whether management interprets the employees' choice of flexible work practices as a signal of high or low organisational commitment.

In sum, the current empirical evidence on the impact of working time flexibility and autonomy on employee performance is quite inconclusive. Moreover, existing studies differ substantially with respect to validity and representativeness, so that the generalisability of these findings is unclear. For example, Bloom et al. (2015), Dutcher (2012), and Leslie et al. (2012) identify causal effects and thus provide reliable evidence for the specific settings that they analyse. In contrast, studies that look at a wider context by analysing more general survey data (e.g., Lyness et al., 2012) exploit cross-sectional data, and thus have only limited means of addressing endogeneity problems, which implies that management implications cannot be drawn from their results. In our study, we apply both representative panel data and estimation strategies that account for a wide range of potential endogeneity problems associated with working under an SMWT regime.

The remainder of the paper is organised as follows: In Section 2, we develop a theoretical model that analyses the consequences of SMWT on employee effort. Section 3 describes the data and variables and provides first empirical insights by discussing some descriptive statistics. The empirical analysis is split in two parts. In Section 4, we investigate the overall impact of SMWT on employee effort, while Section 5 is devoted to a supplementing complementarity analysis that explicitly focusses on the role of worker reciprocity and intrinsic motivation as potential moderating drivers of the SMWT effort effect. In Section 6, we conduct a range of robustness checks that clarify the interpretation of our results, and in Section 7 we use quantile regressions to further explore the heterogeneity of the effect. Finally, Section 8 concludes.

\section{Theoretical model of self-managed working time and effort choice}

We analyse the consequences of SMWT on workers' effort choices by modifying the principalagent approach of Holmstrom and Milgrom $(1987,1990,1991) .^{2}$ Our modifications allow workers to be intrinsically motivated and to reciprocate the employer's offered degree of

\footnotetext{
${ }^{2}$ We do not build on the seminal paper by Aghion and Tirole (1997), because it does not include intrinsic motivation and reciprocity and considers the pure motivational effect of becoming authorised without including incentive contracts.
} 
working time autonomy. Furthermore, we pay attention to a loss of control by the employer due to the workers' higher discretion under SMWT. Finally, we take into account that the employer might compensate the loss of control by the use of alternative control instruments.

In our setting, we consider a risk-neutral, profit-maximizing employer who has to hire a worker in order to run a business. The worker is risk-averse. His utility function is given by $1-$ $\exp (-r \cdot y)$ with $r>0$ denoting the Arrow-Pratt measure of constant absolute risk aversion and $y$ the worker's income. This income may also include perceived income from intrinsic motivation. The worker has the reservation value $\bar{v} \geq 0$ in monetary terms, which indicates his best alternative job opportunity in the labour market.

By choosing non-negative effort $e$, the worker contributes $e$ units to the employer's profit. The employer cannot directly observe the worker's effort choice, but he can make use of the verifiable performance measure $m=e+\varepsilon$. Both $e$ and $\varepsilon$ are unobservable by the employer, which leads to a standard moral-hazard problem. The term $\varepsilon$ describes a normally distributed error or noise component with $\varepsilon \sim N\left(0, \sigma_{A}^{2} / \kappa\right)$. Thus, $m$ is an unbiased estimator of the worker's true effort choice. The variance $\sigma_{A}^{2} / \kappa$ depends on the employer's decision whether to give the worker autonomy over his working time $(A=1)$ or not $(A=0)$. In other words, $A=1$ indicates the choice of SMWT by the employer, whereas $A=0$ describes a working time arrangement with less worker autonomy. We assume that $\sigma_{1}^{2}>\sigma_{0}^{2}$, that is, the introduction of SMWT is accompanied by a higher discretion of a worker, which leads to a less precise monitoring of his daily work by the employer in terms of $1 / \sigma_{1}^{2}<1 / \sigma_{0}^{2}$ (e.g., by the worker's possibility of working at home). The parameter $\kappa>0$ measures the intensity of chosen input and output control by the employer with $\kappa \in\left\{\kappa_{L}, \kappa_{H}\right\}$ and $\kappa_{L}<\kappa_{H}$. Exercising control is costly for the employer. We assume that the employer's costs for choosing $\kappa$ amount to $K(\kappa)>0$ with $K^{\prime}>0$. The performance measure $m$ includes input-related indicators (e.g., control of working time, monitoring daily work) as well as output-related indicators (e.g., control of output quantity and quality). Whereas the introduction of SMWT leads to a loss of control since the employer foregoes an important input-related performance indicator, investment in additional control instruments via $\kappa$ can compensate for this loss. 
We assume that the employer induces extrinsic motivation by offering the linear incentive scheme $w(m)=\alpha+\beta m$, where $\alpha$ is a fixed wage component and $\beta m$ incentive pay based on measured performance. In the following, we look for the optimal contract, consisting of an incentive scheme $w(m)$, a working time regime $A \in\{0,1\}$ and a control intensity $\kappa \in\left\{\kappa_{L}, \kappa_{H}\right\}$.

We further deviate from the Holmstrom-Milgrom framework by introducing intrinsic motivation and reciprocal behaviour. Intrinsic motivation is modelled as in Delfgaauw and Dur (2008) via the worker's (perceived) income function ${ }^{3}$

$$
y=w(m)+\gamma_{A} \cdot V(e)-c(e) \quad \text { with } V(0)=0, V^{\prime}>0, V^{\prime \prime} \leq 0 \text { and } \gamma_{A}>0 .
$$

The term $w(m)-c(e)$ describes the usual earned income minus effort costs. $\gamma_{A} \cdot V(e) \geq 0$ characterises the perceived income from intrinsic motivation, which may depend on the employer's choice of the working time arrangement. Hence, our setup assumes that the worker directly benefits from exerting positive effort. Intrinsic motivation is an individual characteristic of the worker that may be independent of the employer's choice of $A$ (i.e., $\gamma_{1}=\gamma_{0}$ is possible). However, the modelling also allows intrinsic motivation being reinforced by SMWT (i.e., $\left.\gamma_{1}>\gamma_{0}\right)$. This reinforcement is supported by recent findings in behavioural economics. Following the concept of hidden costs of control introduced by Falk and Kosfeld (2006), $A=0$ can be interpreted as choosing control over the worker's daily activity, which destroys part of his intrinsic motivation as the worker feels distrusted by the employer. Social psychological approaches also argue that the reinforcement seems realistic. For example, empowered workers who obtain autonomy over their working time might feel committed to their task, which increases intrinsic motivation (Baron and Kreps, 1999). In addition, under SMWT workers might perceive a stronger internal locus of causality which leads to higher intrinsic motivation according to self-determination theory (Deci and Ryan, 1985, 2000; Turban et al., 2007). To allow for an explicit computation of the optimal incentive scheme, we assume that the perceived income function is linear: $V(e)=I \cdot e$ with $I>0$.

\footnotetext{
${ }^{3}$ Alternatively, intrinsic motivation could be modelled via realised output (e.g., Murdock, 2002). Such approach would have strong parallels to the modelling of feeling committed. A committed worker feels responsible for the produced output and obtains an extra utility when being successful (e.g., Francois, 2000; Besley and Ghatak, 2005; Friebel and Schnedler, 2011; Choe and Ishiguro, 2012).
} 
Reciprocal behaviour by the worker can be motivated via social exchange theory, which was originally introduced by Blau (1964) and Homans (1958), or via the gift-exchange approach, suggested by Akerlof (1982). According to these approaches, a worker might feel obliged to reciprocate in a positive way to benefits provided by the employer. The worker interprets these benefits as signals of recognition for past performance, trust in his work morale or consideration for his work-life balance, and thus responds by exerting additional effort. In the present context, a worker might feel some basic reciprocity by getting a job offer with an interesting task from the employer. Depending on the individual type of worker, these reciprocal feelings can increase if a worker obtains autonomy over his working time, so that he exerts even more extra effort compared to a situation without SMWT. To model reciprocal behaviour in our moral-hazard context, we use the setup suggested by Dur et al. (2010), which focuses on the worker's effort cost function $c(e)$ :

$$
c(e)=\frac{e^{2}}{2}-\delta_{A} e \quad \text { with } A \in\{0,1\} \text { and } \delta_{1} \geq \delta_{0} \geq 0
$$

According to (2), the worker feels non-negative reciprocity, indicated by $\delta_{0} \geq 0$. If $\delta_{0}$ takes its lower bound zero, the worker does not feel any basic reciprocity; otherwise the worker behaves even reciprocally without SMWT. If $\delta_{1}=\delta_{0}$, reciprocity is a purely individualistic trait of the worker and insensitive to the employer's choice of working time arrangement. If $\delta_{1}>\delta_{0}$, the worker positively reciprocates offered SMWT. Technically, in case of zero reciprocity, the worker has a standard quadratic effort cost function and is not willing to choose positive effort without compensation. However, if the worker is reciprocal, then he minimizes effort costs by choosing $e=\delta_{A}$ and he is even willing to choose effort up to $\bar{e}=2 \delta_{A}$ without being paid for it.

The timeline is the following. First, the employer offers a contract $(A, \kappa, \alpha, \beta)$ to the worker, which specifies the working time regime, the monitoring intensity, and the details of the incentive scheme $w(m)$. Then, the worker decides whether to accept the contract or not. If the worker has accepted the contract, he will choose effort $e$, otherwise the game ends and the worker gets his reservation value $\bar{v}$. After the worker accepted the contract and chose effort, the performance measure $m$ is realised and payments to the employer and the worker are made. 
We solve the model by backward induction, starting with the last decision of the two players, i.e., the worker's effort choice. The worker maximises his expected utility or, equivalently, his certainty equivalent

$$
C E=E[y]-\frac{r}{2} \operatorname{Var}[y]=\alpha+\beta e+\gamma_{A} V(e)-\frac{e^{2}}{2}+\delta_{A} e-\frac{r}{2} \beta^{2} \frac{\sigma_{A}^{2}}{\kappa},
$$

which follows from the worker's exponential utility function and noise being normally distributed. ${ }^{4}$ The expression for $C E$ shows that, in a technical sense, positive effects of SMWT (based on intrinsic motivation and reciprocity) and effort are complements. The first-order condition yields the following description of the optimal effort choice, $e^{*}: 5$

$$
\beta+\gamma_{A} V^{\prime}\left(e^{*}\right)-e^{*}+\delta_{A}=0
$$

Implicit differentiation yields $\partial e^{*} / \partial \beta=\partial e^{*} / \partial \delta_{A}=1 /\left[1-\gamma_{A} V^{\prime \prime}\left(e^{*}\right)\right]>0$ and $\partial e^{*} / \partial \gamma_{A}=$ $V^{\prime}\left(e^{*}\right) /\left[1-\gamma_{A} V^{\prime \prime}\left(e^{*}\right)\right]>0$. Thus, the worker's effort rises by an increase in extrinsic and intrinsic motivation, as well as in the degree of reciprocity.

The employer maximises expected profit $E\left[e^{*}-w(m)\right]-K(\kappa)=(1-\beta) e^{*}-\alpha-K(\kappa)$ subject to the incentive constraint (3) and the participation constraint $C E \geq \bar{v}$. Since $\alpha$ does not influence incentives, but increases the employer's labour costs, under the optimal incentive scheme the employer chooses $\alpha$ to make the participation constraint just bind and, hence, to extract all rents from the worker. Solving $C E=\bar{v}$ for $\alpha$ and inserting into the expected profit function shows that the employer chooses $\beta$ to maximise

$$
\pi(A, \kappa):=e^{*}(\beta)+\gamma_{A} V\left(e^{*}(\beta)\right)-\frac{e^{*}(\beta)^{2}}{2}+\delta_{A} e^{*}(\beta)-\frac{r}{2} \beta^{2} \frac{\sigma_{A}^{2}}{\kappa}-\bar{v}-K(\kappa)
$$

with the function $e^{*}(\beta)$ being implicitly described by (3). The first-order condition yields ${ }^{6}$

$$
\left[1+\gamma_{A} V^{\prime}\left(e^{*}(\beta)\right)-e^{*}(\beta)+\delta_{A}\right] \cdot \frac{d e^{*}}{d \beta}-r \beta \frac{\sigma_{A}^{2}}{\kappa}=0
$$

\footnotetext{
${ }^{4}$ See, similarly, Holmstrom and Milgrom (1990, p. 88), Holmstrom and Milgrom (1991, p. 29).

5 The second-order condition $\gamma_{A} V^{\prime \prime}(e)-1<0$ is satisfied.

${ }^{6}$ The second-order condition is clearly satisfied for our specification of $V(e)$, see below.
} 
By using the parametric specification for the perceived income introduced above, $V(e)=I \cdot e$, the incentive constraint (3) becomes $e^{*}(\beta)=\beta+\gamma_{A} I+\delta_{A}$ and the first-order condition (5) reduces to $\beta^{*}=1 /\left[1+\left(r \sigma_{A}^{2} / \kappa\right)\right]$ as description of the optimal extrinsic incentives. The result for $\beta^{*}$ shows that the following trade-off exists: The larger a worker's degree of risk aversion, $r$, and the smaller the overall precision of the performance measure, $\kappa / \sigma_{A}^{2}$, the lower powered will be optimal extrinsic incentives. This finding is not specific to linear incentive schemes but also holds qualitatively for non-linear schemes (see the incentiveintensity principle highlighted by Milgrom and Roberts, 1992). $\beta^{*}$ also shows that extrinsic motivation crucially depends on the working time arrangement and the control intensity. Since SMWT leads to a loss of control in the sense of $\sigma_{1}^{2}>\sigma_{0}^{2}$, for a given control intensity $\kappa$, optimal extrinsic incentives will be lower powered under SMWT compared to working time arrangements that allow less worker discretion. However, the employer might prefer to combine the different working time arrangements $A=1$ and $A=0$ with different control intensities. In particular, the employer might prefer to combine SMWT (i.e., $A=1$ ) with a high control intensity $\kappa=\kappa_{H}$ to compensate for the loss of control due to higher worker discretion, and to combine $A=0$ with $\kappa=\kappa_{L}$ because control of the working time already ensures a sufficiently precise performance measure $m$. To illustrate the possibility of such specific combinations of working time arrangement and control intensity, we replace $\kappa$ by $\kappa(A)$ in the following, where $\kappa(A)$ denotes the optimal control intensity under optimal extrinsic incentives and the working time regime $A$.

At the first stage of the game, the employer chooses the contract $(A, \kappa, \alpha, \beta)$ that maximizes his objective function (4). This optimal contract will comprise $A=1$ if and only if $\pi(1, \kappa(1)) \geq$ $\pi(0, \kappa(0))$ or, equivalently,

$$
\left(2+\Psi_{1}\right) \Psi_{1}-\left(2+\Psi_{0}\right) \Psi_{0} \geq \frac{1}{1+r \frac{\sigma_{0}^{2}}{\kappa(0)}}-\frac{1}{1+r \frac{\sigma_{1}^{2}}{\kappa(1)}}+2 \cdot[K(\kappa(1))-K(\kappa(0))]
$$

with $\Psi_{A}:=\delta_{A}+\gamma_{A} I$ denoting that part of the induced optimal effort $e^{*}(\beta)$ that is due to intrinsic motivation and reciprocal behaviour. Suppose, for a moment, that the difference in monitoring 
costs, $K(\kappa(1))-K(\kappa(0))$, is zero as the employer chooses the same monitoring intensity under $A$ $=0$ and $A=1$ or that the difference is negligible. Condition (6) then shows that the employer will prefer SMWT if the additional incentives from intrinsic motivation and reciprocity are sufficiently large such that they dominate the possible disadvantage from a loss of control, which leads to higher labour costs as the employer has to compensate the worker for a higher risk premium. ${ }^{7}$ We only speak of a possible disadvantage because, depending on $K(\kappa)$, the employer might prefer $\kappa(1)=\kappa_{H}$ but $\kappa(0)=\kappa_{L}$ to compensate for the loss of control under SMWT. In that case, it is possible that $\sigma_{1}^{2} / \kappa_{H} \leq \sigma_{0}^{2} / \kappa_{L}$ so that extrinsic incentives are restored. All in all, the employer's optimal contract will include $\kappa=\kappa_{H}$ instead of $\kappa=\kappa_{L}$ if, for given $A \in\{0,1\}$, the advantage of an increased precision of the performance measure exceeds the disadvantage in form of higher monitoring costs.

Finally, we can investigate whether SMWT leads to more or less effort compared to the working time regime $A=0$. Inserting $\beta^{*}$ into $e^{*}(\beta)$, using the notation $\kappa(A)$, and comparing the implemented optimal efforts under $A=0$ and $A=1$ shows that SMWT will lead to higher effort if and only if

$$
\Psi_{1}-\Psi_{0} \geq \frac{1}{1+r \frac{\sigma_{0}^{2}}{\kappa(0)}}-\frac{1}{1+r \frac{\sigma_{1}^{2}}{\kappa(1)}} \Leftrightarrow \delta_{1}-\delta_{0}+\left(\gamma_{1}-\gamma_{0}\right) I \geq \frac{1}{1+r \frac{\sigma_{0}^{2}}{\kappa(0)}}-\frac{1}{1+r \frac{\sigma_{1}^{2}}{\kappa(1)}}
$$

In words, the introduction of SMWT will boost worker effort if and only if the effort increase via intrinsic motivation and reciprocal behaviour exceeds the possible effort decrease from lower powered extrinsic incentives. Note that the left-hand side of (6) is larger than the left-hand-side of (7). Thus, if the employer chooses the same control intensity under both working time regimes, condition (7) will already imply condition (6) so that SMWT will always be optimal if it leads to higher effort. We use condition (7) to establish two opposing hypotheses.

\section{HYPOTHESIS 1. Incentives from intrinsic motivation and reciprocity dominate the possible} loss in extrinsic motivation so that SMWT leads to extra effort compared to other working time arrangements that give less discretion to workers.

\footnotetext{
${ }^{7}$ Recall that the participation constraint is binding under the optimal contract so that the employer has to compensate the worker for the whole risk premium.
} 
In contrast, if a worker's intrinsic motivation and reciprocity are not very strong, or if they are not context dependent but belong to the personal traits of a worker, extra incentives from the introduction of SMWT will be negligible. If, at the same time, the large autonomy over working time yields a considerable loss of control and the costs for additional control, $K\left(\kappa_{H}\right)-K\left(\kappa_{L}\right)$, are quite large, the overall incentive effect of SMWT will become negative.

HYPOTHESIS 2. The loss of control from larger worker autonomy dominates the incentives from intrinsic motivation and reciprocity so that SMWT leads to lower effort compared to other working time arrangements that give less discretion to workers.

\section{Data, variables and descriptive statistics}

Our empirical analysis is based on data from the German Socio-Economic Panel (SOEP). Starting in 1984, the SOEP is an annual longitudinal survey of about 22,000 individuals living in about 12,000 private households. The questionnaires cover a wide range of individual and jobrelated characteristics. Job-related characteristics, for example, include employment and occupational status, type of work contract, training, working conditions and working time arrangements, professional mobility, earnings, and job satisfaction. In addition, the SOEP contains a number of individual characteristics such as education, personality traits, living circumstances, health and individual well-being, family biographies, career history and household composition. The SOEP even includes some characteristics at the firm level, such as firm size, sector affiliation and works council presence. Some of the items are surveyed annually, while others are captured at more or less regular time intervals. ${ }^{8}$ All in all, the SOEP is probably the most established and representative survey data set at the individual level in Germany, and one of the largest and longest running household panel studies in Europe.

In order to examine the relationship between SMWT and employee effort, we utilise the SOEP waves of 2003, 2005, 2007, 2009 and 2011. These five panel waves contain information about both the different forms of working time arrangements and measures of employee effort.

\footnotetext{
${ }^{8}$ For more comprehensive information about the SOEP, see Wagner et al. (2007).
} 
We restrict the analysis to private and public sector employees and exclude self-employed persons, civil servants and apprentices. ${ }^{9}$ Workers in the sample are aged between 17 and 65 .

Workers are assigned to the respective working time regimes according to their answers to the following survey question: "Which of the following working hours arrangements is most applicable to your work?" Respondents could choose between four items.

- Fixed daily working hours

- Working hours fixed by employer, which may vary from day to day

- Flexitime within a working hours account and a certain degree of self-determination of daily working hours within this account

- Working hours fixed by employee, which may vary from day to day (SMWT).

Table 1 displays the incidence of the different working hours regimes between 2003 and 2011. The table demonstrates that fixed daily working time is still the most common form of working hours arrangements. It applies to about $43 \%$ of the employees in Germany. About $20 \%$ of the workers make use of flexitime within a working hours account. Furthermore, about 22.5\% of employees work flexible hours that are determined by the employer. Finally, about $14.5 \%$ of the employees report having the freedom to determine working time at their own discretion. Table 1 also indicates that the percentages for each of the working time regimes remained quite stable over the past decade.

[Insert Table 1 and Table 2 about here]

Table 2 provides some information about work effort in each of the four working time regimes. As our main measure of extra effort, we use the difference between average actual working hours $\left(W H^{a}\right)$ and contractual working hours $\left(W H^{c}\right)$ per week, labelled $\Delta W H=W H^{a}-W H^{c}$. Although extra working time is an established measure of employee effort in the literature (e.g., Bell and Freeman, 2001), we also explore alternative performance

\footnotetext{
${ }^{9}$ Self-employed individuals are excluded, because they are their own boss by definition. Thus, they are able to choose their working hours freely and may also lack a clear workplace definition (Eldridge and Pabilonia, 2010; Golden, 2009). In addition, we remove obvious outliers from our sample. Specifically, we eliminate individuals who reported unrealistically low monthly gross wages. Consequently, our sample includes workers who earn at least 400 Euros per month. In Germany, workers with a monthly gross wage of up to 400 Euros (450 Euros since 2012) are often called 'mini-jobbers'.
} 
measures used in the literature (such as absenteeism and hourly wages) to shed some light on the question of whether extra time spent at work is used productively or not (see Section 6).

The first striking result in Table 2 is that, on average, workers provide some extra effort in each of the four working time arrangements. However, there are substantial differences between the categories with respect to the extent of extra effort. While, on average, $\Delta W H$ is relatively small in the fixed working time regime (2.2-2.7 hours per week), the largest amount of extra effort can be ascertained for employees with SMWT (6.9-8.1 hours per week). According to this finding, employees with SMWT provide, on average, an extra effort of up to one additional working day per week (in fulltime equivalents), which is about five hours more than workers in a fixed working time regime deliver.

Of course, these descriptive statistics only provide some first insights about average effort differences between the working time regimes. Conclusions regarding a meaningful effort effect of SMWT (and other working time arrangements) can only be drawn from multiple regression analyses that explicitly account for potential endogeneity bias.

\section{Effort effects of self-managed working time}

This section is devoted to the question whether or not SMWT has an impact on worker effort, thus testing the general implications of condition (7) in our theoretical model that leads to the derivation of Hypotheses 1 and 2. We expect the overall incentive effect to be positive if the effort increase induced by SMWT via reciprocal behaviour and intrinsic motivation is stronger than the potential effort decrease, which may result from the fact that SMWT is associated with a loss of employer control. Conversely, we expect a negative effect of SMWT on worker effort if the reverse is true.

\subsection{Econometric model and estimation strategy}

In order to measure the impact of SMWT on worker effort, we specify the following fixed effects model:

$$
\Delta W H_{i t}=\alpha_{1} S M_{i t}+\alpha_{2} E D_{i t}+\alpha_{3} F T_{i t}+J A_{i t} \lambda+X_{i t} \beta+\mu_{i, j(i t)}+u_{i t}
$$


The dependent variable $\Delta W H$ measures the amount of extra effort (as defined above) of employee $i$ at time $t$. Our main explanatory variables are dummy variables for three of the four working hours regimes, i.e., SMWT ( $S M$ ), flexible working time determined by the employer ( $E D$ ), and flexitime ( $F T$ ). The coefficients $\alpha_{1}, \alpha_{2}$ and $\alpha_{3}$ must be interpreted relative to the excluded reference group of the fixed working time regime, where for our purpose $\alpha_{1}$ is of particular interest. $J A$ is a vector of dummy variables measuring the degree of overall job autonomy. The vector $X$ contains a rich set of socio-economic control variables which we discuss in the remainder of this section, and for which we provide detailed definitions and descriptive statistics in the supplementary material (see Table S5 of the supplementary material). Finally, $u$ is an idiosyncratic error term with zero mean and finite variance, and $\mu_{i, j(i t)}$ is a worker-firm spell fixed effect. The subscript $j(i t)$ stands for the firm $j$ in which worker $i$ is employed at time $t . \mu_{i, j(i t)}$ is equivalent to the inclusion of dummy variables for all unique worker-firm combinations, and it controls for worker fixed effects and firm fixed effects as well as their combination.

The inclusion of worker-firm spell fixed effects implies that the variation we exploit results from changes in SMWT that workers experience while being employed in the same firm, thus holding time-invariant unobserved worker and firm characteristics constant. This is important to account for potential endogeneity of SMWT and associated bias in $\alpha_{1}$ that would arise if more motivated workers choose to work under SMWT, or if firms that require higher effort from their workers (or that offer more incentives for effort) are more likely to operate SMWT.

However, including worker-firm spell fixed effects does not yet deal with endogeneity based on time-varying characteristics. Our first strategy to address this issue is to control for a vast range of observed time-varying characteristics that may affect worker effort and could be correlated with changes in SMWT. For example, firms that introduce SMWT may grant more autonomy also in other job dimensions, or they may assign more challenging or interesting tasks. These factors may increase worker effort and, if not controlled for, would be spuriously picked up by the SMWT coefficient $\alpha_{1}$. In particular, we control for an employee's overall job autonomy by including a set of dummy variables for different levels of occupational job 
autonomy summarized in $J A .{ }^{10}$ Moreover, the vector $X$ includes an extremely rich set of almost 1,300 occupation dummies. ${ }^{11}$ As workers can change occupations at the same firm this partly controls for changes in task content. We further include a variable on job satisfaction, which proxies for confounding factors potentially related to SMWT to the extent that they affect worker effort through perceived job satisfaction.

In addition, $X$ contains individual characteristics such as years of schooling, gender, nationality, marital status, the existence of children in the household, health status, satisfaction with health and household income, as well as the number of hours devoted to leisure-time activities. Besides occupation dummies and job satisfaction, it also includes further job characteristics that may influence a worker's extra effort, i.e., wage level, job tenure, employment status (full-time or part-time, permanent or fixed-term), employer changes, perceived job security, and previous experiences with full-time and part-time jobs as well as unemployment. We also add firm-level information (firm size class and sector affiliation of the respondent's company) to the vector of control variables. Moreover, $X$ also includes a set of time dummies. Finally, in addition to the information provided by the survey, we match average annual unemployment rates of the different German federal states as published by the German Federal Statistical Office to our data. Table S5 (see the supplemental material) provides the definitions and descriptive statistics of the complete set of variables used in this study.

Our second strategy to account for time-varying unobserved heterogeneity is an instrumental variables estimation approach exploring lagged working time arrangements and a group-specific share of SMWT workers as instruments, which is extensively discussed in the supplemental material. Finally, in Section 6 we check whether our results are robust to additionally controlling for changes in contractual working time that might be confounded with SMWT, and whether the results hold across a range of different measures of worker performance as dependent variable.

\footnotetext{
10 The job autonomy dummy variables are generated from an ordinally scaled variable ranging from 0 to 5 , where higher values represent higher levels of job autonomy. The original autonomy variable called AUTONO\$\$ was constructed by the SOEP and provides information on the occupational autonomy for all employed individuals. For more details see the SOEP report 'Documentation PGEN - Person-related status and generated variables' under https://www.diw.de/documents/dokumentenarchiv/17/diw_01.c.60055.de/pgen.pdf (p. 31) and the variables descriptions in the supplemental material (Table S5).

11 This provides a very detailed picture. For example, the general occupation of waiter/waitress is broken up into several occupational codes, such as assistant waiter, waiter, senior waiter, bartender, and bar mixologist.
} 


\subsection{Empirical results}

Table 3 displays the estimation results for the impact of SMWT on employee extra effort, as measured by $\Delta W H$. Column (1) contains the conventional ordinary least squares (OLS) estimates of an unconditional specification, where the dependent variable is solely regressed on the working time regime dummies and a constant. Column (2) describes the OLS estimates of the working time regime and the overall job autonomy dummies conditional on the complete set of covariates, while column (3) shows the marginal effects resulting from a Tobit maximum likelihood (ML) estimation. ${ }^{12}$ The Tobit model accounts for the fact that $\Delta W H$ has a mass point of values at zero, while negative values, though theoretically possible, are relatively scarce. Both OLS and Tobit ML estimates are unlikely to provide consistent estimates of $\alpha_{1}, \alpha_{2}$ and $\alpha_{3}$, unless $S M$ and the other working time variables are strictly exogenous, i.e., uncorrelated with both the unobserved worker-firm spell fixed effect, $\mu_{i, j(i t)}$, and the idiosyncratic error term, $u_{i t}$. Hence, column (4) displays the fixed effects (FE) estimates of $\alpha_{1}, \alpha_{2}$ and $\alpha_{3}$ from equation (8) using the within estimator. ${ }^{13}$ This allows us to eliminate an endogeneity bias that is caused by time-invariant unobserved factors.

\section{[Insert Table 3 about here]}

The most striking result of our estimates is that throughout all specifications SMWT has a positive influence on employee extra effort, which confirms Hypothesis 1. However, the magnitude of the positive impact sharply declines when accounting for observed heterogeneity in columns (2) and (3) as well as for time-constant worker- and firm-specific unobserved heterogeneity in column (4). Starting with an initial estimate of about 5 hours per week in the unconditional specification, the effect on average extra effort reduces to 3.3 hours in the complete OLS model or 2.7 hours in the corresponding Tobit specification, respectively, and finally ends up with a point estimate of 1.3 hours in the FE model. ${ }^{14}$ Put differently, from the

\footnotetext{
12 The control variables in Table 3 do not include performance evaluation, intrinsic motivation, and reciprocity that we have highlighted in the theory section. These will be added to our empirical analysis in Section 5. As we show below in Table 5, their inclusion does not change our main results in Table 3.

${ }^{13}$ All estimates that are not reported in the tables of this paper are available from the authors upon request. Summary statistics and a correlation matrix for major dependent and independent variables can be found in the supplemental material (see Tables S3 and S5).

${ }^{14}$ We also estimated a random effects (RE) Tobit model that was extended with additional regressors capturing the worker-firm-specific means over time for all time-varying covariates (Mundlak's approach). This model was used
} 
initial 5 hours of extra effort obtained in the unconditional OLS estimation about 1.7 hours can be explained by observed individual, job or firm characteristics other than SMWT. From the remaining 3.3 hours, about 2 hours can be attributed to unobserved factors, leaving an effect of approximately 1.3 hours that can be ascribed to the policy of SMWT itself. This is about $26 \%$ of the initially estimated impact.

Our main conclusions from these results are twofold. First, controlling for selection into SMWT (based on unobserved time-invariant worker and firm characteristics) and for changes in the workplace environment potentially related to SMWT (based on a large set of time-varying workplace characteristics) clearly matters, as it reduces the positive effort effect of SMWT considerably. Second, there remains a moderate positive effect. The $95 \%$ confidence interval from our preferred FE estimate ranges between 1.0 and 1.7 hours. Therefore, our findings document that Hypothesis 2 assuming a negative effect of SMWT on workers' effort choice can be clearly rejected. ${ }^{15}$ On the contrary, compared to the fixed working hours arrangement there remains a positive regime effect of about 80 minutes of excess working time per week, which supports Hypothesis 1. Additional instrumental variables estimates produce very similar results (here, the SMWT effect is approximately 1.5 hours of extra working time per week) and the associated endogeneity tests show that after controlling for worker-firm spell fixed effects there remains no further endogeneity, which would suggest that the FE estimate of $\alpha_{1}$ can be interpreted as a causal effect. An extensive discussion on this issue can be found in the supplemental material.

\section{Complementarity analysis}

In this section, we go more into the details of our theoretical model derived in Section 2. According to our empirical findings discussed in the previous section, the overall incentive effect of SMWT is positive. This suggests that incentives from intrinsic motivation and worker reciprocity dominate the opposing incentive effect due to a loss of employer control associated

\footnotetext{
because the FE Tobit model leads to inconsistent parameter estimates (e.g., Baltagi 2008). The SMWT effect obtained in this regression is highly significant and larger than the conventional FE estimate (2.808 vs. 1.346). Since the FE estimate is more conservative than its counterpart obtained from the RE Tobit-Mundlak model, and $\Delta W H$ is not strictly censored at zero (because some negative values can be observed), we decided to continue with the FE estimates and did not incorporate the RE Tobit-Mundlak model into Table 3.

${ }^{15} \mathrm{We}$ will come back to this point in a more detailed discussion in Section 7.
} 
with SMWT. In the following, we aim at disentangling this positive overall incentive effect by asking whether SMWT increases worker reciprocity, intrinsic motivation, or both. If SMWT indeed promotes the workers' intrinsic motivation or positive reciprocity, then these worker characteristics and SMWT are complements in producing effort. Identifying such complementarities enables us to refine the management implications to be drawn, because we can then establish under which circumstances the introduction of SMWT has the strongest effort effects.

\subsection{Econometric modelling}

By definition, complementary items have a larger performance impact when utilised jointly rather than separately, and hence, their interaction effect on performance is positive. In this section, we therefore test for positive interaction effects by augmenting our preferred FE model (8) with interaction terms on SMWT and the worker characteristics of intrinsic motivation and reciprocity.

In order to be able to precisely estimate the interaction terms of interest, it is important to augment the econometric model not only with proxies for intrinsic motivation and worker reciprocity, but also with a measure that reflects the potential impact of extrinsic motivation on employee effort. Recall from our theoretical model in Section 2 that the employer might be interested in choosing a high control intensity $\kappa=\kappa_{H}$ to compensate for the loss of control from SMWT. In practice, the introduction of SMWT may be accompanied by a measure for monitoring employee output as a substitute for the rescinded duty to register working hours. ${ }^{16}$ In our econometric analysis, we address this idea by including a human resource policy measure aimed at increasing extrinsic motivation. Specifically, we add a dummy variable for performance evaluation, $P E$, which indicates whether or not an employee's performance is regularly evaluated by a supervisor. ${ }^{17}$ Not controlling for extrinsic motivation involves the risk that an

\footnotetext{
${ }^{16}$ Based on case studies, Moen et al. (2011a, 2011b) analyse such scenarios, which they call 'results only work environment (ROWE)'.

${ }^{17}$ The information about performance evaluations was originally only surveyed in 2004, 2008 and 2011 . We replaced the missing values by imputing the 2004 observations to 2003 and 2005, and by imputing the 2008 observations to 2007 and 2009. Imputation might be inappropriate when workers switched employers. Our results are, however, virtually the same when we re-estimate equation (15) on a sample of workers who stayed with their employer.
} 
effort effect, which is effectively caused by extrinsic motivation, would falsely be attributed to intrinsic motivation or worker reciprocity.

Recall first that according to self-determination theory employees who perceive a stronger internal locus of causality are likely to exert a higher effort level due to increased intrinsic motivation. Working under an SMWT arrangement should strengthen the perception of an internal locus of causality, and this might be the reason for the positive effort effect of SMWT that was identified previously. Technically, in our model in Section 2, the left-hand side of condition (7) increases in the intrinsic motivation parameter $I$ if $\gamma_{1}>\gamma_{0}$, i.e., if intrinsic motivation under SMWT is higher than under a working time arrangement with less worker autonomy.

We test for such a complementary relationship by interacting our SMWT variable in the working hours regression with a measure for intrinsic motivation. For this purpose, we make use of a variable that gives information about an employee's work morale or work attitude, respectively. More precisely, we consider the responses of the surveyed individuals to the question: "If you could choose your own number of working hours, taking into account that your income would change according to the number of hours: How many hours would you want to work?" From this we construct a binary measure of intrinsic motivation $I M$ that takes the value 1 if a worker's desired weekly working hours are equal or higher than his contractual weekly hours, and the value 0 if the desired hours fall short of contractual working time. Hence, we assume that the desire to work at least as much hours as contractually agreed serves as a signal for an employee's sensation of joy at work, commitment to the job, or his aspiration level concerning work attitude or work morale.

This assumption would be violated in the following cases. First, workers may wish to work longer hours because their current work load is so high that they are not able to finish their tasks within their contractually agreed working hours. Second, workers may be extrinsically motivated to work longer hours in order to earn more money by changing from part-time to full-time employment or in order to increase their probability of receiving an overall pay rise or a promotion. To provide evidence supporting the idea that $I M$ indeed measures intrinsic motivation, as opposed to work load or extrinsic motivation, we restrict our sample to full-time workers and regress $I M$ on a number of proxies for work load ("Work strain”, "Time 
pressure"), extrinsic motivation ("Paid overtime", "Expected promotion", Expected pay rise"), and various dimensions of intrinsic motivation ("Job satisfaction”, "Sacrifice”, "Unpaid overtime", "Hard-working”, “Thorough", “Task efficiently”, “Joy at work”). The results and the precise variable definitions are reported in Table 4. Each row of the table represents results from a separate linear regression where $I M$ is regressed on each of the single indicator variables separately. ${ }^{18}$

\section{[Insert Table 4 about here]}

The results are striking. While all the indicators for intrinsic motivation are highly significant and positively associated with $I M$, none of the work load or extrinsic motivation indicators is positively related to $I M$. Both work load indicators and paid overtime are even negatively associated with $I M$. An employee's desire to work at least as much hours as contractually agreed thus indicates joy at work, (over)commitment to the job, or a high job-related aspiration level, and thus expresses typical dimensions of intrinsic motivation.

Furthermore, recall that according to social exchange theory and the gift-exchange approach, a worker may be encouraged to provide extra effort as an act of positive reciprocity in response to being granted SMWT. In our theoretical model discussed in Section 2, this idea is explicitly considered as condition (7) will be more likely to be satisfied if $\delta_{1}>\delta_{0}$. Thus, we would expect the effort effect of reciprocity to be stronger for SMWT workers than for employees who do not work under an SMWT arrangement. We test this idea by interacting our SMWT variable with a binary measure $R$ that distinguishes high-level from low-level reciprocators. We constructed $R$ from the respondent's degree of approval, measured on a 7-point Likert scale ranging from 1 (“does not apply to me at all") to 7 ("applies to me perfectly"), to the following statements: (a) "If someone does me a favour, I am prepared to return it." (b) "I go out my way to help somebody who has been kind to me before." (c) "I am ready to bear personal costs to help

\footnotetext{
${ }^{18}$ As indicated in the last column of Table 4, the reason for running separate regressions rather than incorporating all indicators into one regression model lies in their very different availability across the panel waves. Limited availability across the panel waves is also the reason why most of the intrinsic motivation proxies in Table 4 could not be used as the main $I M$ indicator. Only job satisfaction and the share of unpaid overtime are surveyed annually. We did not use job satisfaction as a measure for $I M$ because this measure is an overall measure also including dimensions other than intrinsic motivation, such as satisfaction with pay, promotion prospects, or supervision. Furthermore, we did not use the share of unpaid overtime as our $I M$ measure because whether overtime is paid or unpaid depends partly on the employer, occupation and industry, and thus it is unclear to what extent the share of unpaid overtime indeed reflects worker preferences or motivation.
} 
somebody who helped me before." For each individual we calculated the average across the three questions and defined $R$ to be equal to one if an individual's average equals or exceeds the median, and equal to 0 if it is below the median. ${ }^{19}$ Our regression model can then be written as

$$
\begin{aligned}
\Delta W H_{i t} & =\alpha_{11} S M_{i t}+\alpha_{2} E D_{i t}+\alpha_{3} F T_{i t}+\pi_{1} I M_{i t}+\pi_{2} R_{i t}+\pi_{3} P E_{i t} \\
& +\pi_{4} I M_{i t} \times S M_{i t}+\pi_{5} R_{i t} \times S M_{i t}+\pi_{6} P E_{i t} \times S M_{i t}+J A_{i t} \lambda+X_{i t} \beta+\mu_{i, j(i t)}+u_{i t} .
\end{aligned}
$$

Here, $\pi_{1}$ indicates the effect of intrinsic motivation on $\Delta W H$ for workers without SMWT, while $\pi_{1}+\pi_{4}$ captures the corresponding effect for SMWT workers. The term $\pi_{1}$ corresponds to $\gamma_{0}$ in our theoretical model, while $\pi_{1}+\pi_{4}$ is the empirical analogue for $\gamma_{1}$. As a result, $\pi_{4}>0$ would support our theoretical prediction $\gamma_{1}>\gamma_{0}$. In addition, $\pi_{4}>0$ would indicate complementarity between SMWT and intrinsic motivation implying that SMWT is particularly effective when targeted towards intrinsically motivated workers. This leads to the following hypothesis:

HYPOTHESIS 3. The effort effect of intrinsic motivation is stronger for SMWT workers than for non-SMWT workers, so SMWT and intrinsic motivation are complements in producing worker effort.

Moreover, $\pi_{2}$ measures the effect of positive reciprocity on $\Delta W H$ for workers without SMWT, while $\pi_{2}+\pi_{5}$ indicates the corresponding effect for SMWT workers. Note that $\pi_{2}$ corresponds to $\delta_{0}$ in our theoretical model, while $\pi_{2}+\pi_{5}$ reflects $\delta_{1}$. Hence, $\pi_{5}>0$ would confirm the theoretical prediction $\delta_{1}>\delta_{0}$. Furthermore, $\pi_{5}>0$ would indicate a complementary association between SMWT and reciprocity implying that SMWT is particularly effective when targeted towards positively reciprocating workers. We can therefore state the following hypothesis:

HYPOTHESIS 4. The effort effect of positive reciprocity is stronger for SMWT workers than for non-SMWT workers, so SMWT and reciprocity are complements in producing worker effort.

\footnotetext{
${ }^{19}$ Information about reciprocity is originally surveyed only in 2005 and 2010 . We therefore replaced the missing values by imputing the 2005 observations to the years 2003 and 2007, and by imputing the 2010 observations to the years 2009 and 2011. This procedure should not be problematic, because personality traits are unlikely to change very quickly over time. For a short summary of the debate on whether personality traits can be assumed to be timeconstant or time-varying, see Heineck and Anger (2010).
} 
Finally, $\pi_{6}>0$ would indicate complementarity between SMWT and performance evaluations implying that it is more effective to introduce SMWT jointly with measures of output control.

\subsection{Empirical results}

Table 5 displays the parameter estimates of the SMWT variable ( $S M$ ) as well as the intrinsic motivation ( $I M)$, reciprocity $(R)$, and performance evaluation $(P E)$ variables, and the corresponding interaction effects. The specification in column (1) extends equation (8) by including $I M, R$, and $P E$ and shows that, compared to the results in column (4) of Table 3, the SMWT effect is barely affected by the inclusion of these additional variables. The remainder of Table 5 is restricted to full-time workers for whom our IM measure is more reliable (see the discussion in Section 5.1). As column (2) shows, this restriction leads to a moderate increase in the SMWT coefficient compared the effect in column (1) (1.657 vs. 1.289, corresponding to about 100 minutes more working hours per week vs. about 80 minutes). Moreover, we find that both intrinsic motivation and reciprocity affect employee extra effort positively, but the effect of intrinsic motivation exceeds the reciprocity effect in terms of size and significance. On the contrary, performance evaluations do not contribute to increased worker effort significantly. The finding that the main SMWT effect does not decline when including the performance pay variable is important, because it suggests that the SMWT effect is not simply driven by the fact that firms have replaced their previous input monitoring activities (recorded working hours) by output monitoring via performance evaluation.

\section{[Insert Table 5 about here]}

In column (3) we present the results from the estimation of equation (9), allowing for complementarity between SMWT and $I M, R$ and $P E$. In column (4) we extend that specification by breaking $P E$ up in two types of performance evaluation, with and without consequences on pay or promotion $\left(P E_{1}\right.$ and $\left.P E_{2}\right) \cdot{ }^{20}$ Our results demonstrate a distinct

\footnotetext{
${ }^{20}$ Performance evaluations with consequences have an influence on an employee's monthly gross salary, yearly bonus payments, future salary increases, or potential promotions. Distinguishing between performance evaluations with and without consequences might roughly correspond to the distinction of formal versus informal performance evaluation. However, we cannot entirely rule out that some subtle forms of informal performance evaluation may not be picked up by our performance evaluation measure.
} 
complementary relationship between intrinsic motivation and SMWT. The positive and statistically significant coefficient on the interaction term $I M \times S M-$ corresponding to $\pi_{4}$ in equation (9) - implies that the combination of being intrinsically motivated and working under SMWT yields an extra effort effect over and above the sum of the two separate effects of being only intrinsically motivated $\left(\pi_{1}\right)$ and of working only under SMWT $\left(\alpha_{11}\right)$. In particular, $\pi_{4}=0.816$ in column (3) and $\pi_{4}=0.824$ in column (4), both significant at the $5 \%$ level, suggest that the effect of intrinsic motivation on extra effort is about 50 minutes per week higher for workers with SMWT than for workers without SMWT, confirming our theoretical prediction $\gamma_{1}>\gamma_{0}$ from Hypothesis $3 .{ }^{21}$ At the same time, the positive interaction effect also implies that intrinsically motivated workers have a higher SMWT effect (amounting to $1.053+0.816=1.869$ hours; see column (3)) than not intrinsically motivated workers (whose SMWT effect is 1.053).

Turning to Hypothesis 4, we note from Table 5 that the interaction effect of SMWT with reciprocity $R \times S M$ - corresponding to $\pi_{5}$ in equation (9) - is 0.088 in column (3) and 0.095 in column (4), both times not significantly different from zero. This implies that we cannot find empirical support for our theoretical prediction $\delta_{1}>\delta_{0}$ and suggests that SMWT does not amplify a worker's level of reciprocity, and thus, reciprocity is not found to be complementary to SMWT in producing extra effort. This finding is in line with Giardini and Kabst (2008) who argue that German employees might not perceive the employer's provision of work-family practices (such as SMWT) as a special benefit that would elicit a sense of obligation in them to reciprocate. Instead, due to Germany's long tradition as a social market economy, German employees are assumed to expect a lot from their employers, which explains their lack of reciprocity. If indeed specific characteristics of the German labour market are responsible for the missing impact of reciprocity, this fact will even strengthen our general findings on the positive incentive effects of SMWT. In that case, the sole effect of intrinsic motivation complemented by SMWT already leads to extra incentives in the German labour market. Due to additional incentives from reciprocity, the positive incentive effect of SMWT must therefore be even larger in those labour markets that lack the German characteristic mentioned above.

\footnotetext{
${ }^{21}$ For workers without SMWT, the effect of intrinsic motivation in column (2) is 0.687 (about 40 minutes per week), whereas this is $0.687+0.816=1.503$ (about 1 hour and 30 minutes per week) for workers with SMWT.
} 
Performance evaluations, however, do not increase the SMWT effect. This holds for both the combined performance evaluation measure (column (3) of Table 5) and the separate performance evaluation measures that differentiate between performance evaluations with and without consequences (column (4) of Table 5). The interaction terms of SMWT with performance pay $P E \times S M$ - corresponding to $\pi_{6}$ in equation (9) - are statistically insignificant. Hence, we conclude that intrinsic motivation is strongly complementary to SMWT, but reciprocity and performance evaluations are not. From a management perspective, SMWT is therefore likely to boost worker effort the most if it is targeted towards highly self-motivated workers, whereas accompanying performance evaluations do not seem to be necessary to keep worker effort high. Intrinsic motivation should therefore be a criterion for selecting employees into SMWT arrangements.

\section{Alternative performance measures}

In this section, we probe the robustness of our results and try to gain additional insight on how to interpret the previous results by using a range of different performance measures. We report the results in Table 6, which presents the respective SMWT coefficient $\alpha_{1}$ resulting from different estimation approaches.

\section{[Insert Table 6 about here]}

In Panel A of Table 6, we use alternative measures of extra work, which are all based on hours of working time. Recall that in our baseline specification the dependent variable $\Delta W H$ is defined as an employee's actual working time minus his contractual working time. Throughout the paper, we interpret the positive SMWT effect on $\Delta W H$ as an increase in workers' extra effort. However, this interpretation would be wrong if firms routinely reduced contractual working time after the introduction of SMWT. ${ }^{22}$ Then, $\Delta W H$ would increase without any increase in actual working time, and the interpretation of the effect in terms of extra effort would

\footnotetext{
${ }^{22}$ Recall in this context our descriptive results displayed in Table 2, according to which SMWT employees, on average, indeed appear to be faced with slightly lower contractual working hours than employees in the other working time arrangements. We also ran an auxiliary FE regression model, where contractual working hours were regressed on SMWT and the same set of covariates that was also applied to produce the estimates of Table 3 , column (4). The SMWT effect on contractual working hours is negative and highly significant, albeit quite moderate (coefficient: -0.332 - corresponding to about 20 minutes less working time per week than the contractual weekly working time of employees in a fixed working time regime -, standard deviation: 0.118).
} 
be flawed. In the first row of Panel A we therefore test to what extent our results may be driven by changes in contractual working hours by adding contractual working hours as a covariate to our baseline specification of equation (8). Holding contractual working hours constant in that way ensures that any resulting SMWT effect can only be driven by increases in actual working time. The OLS and FE effects for this robustness check are reported in columns (1) and (2) of Table 6, respectively. The effects are very similar to our baseline results of columns (2) and (4) in Table 3 and thus rule out that our main results are driven by systematic changes in contractual working hours. ${ }^{23}$

In the remaining rows of Panel A, we present further robustness checks where we reestimate our baseline specification of equation (8) using alternative measures of extra work. First, we use the amount of self-reported overtime work in the recent month prior to the survey (overtime last month). In addition, we use a measure labelled $\Delta \mathrm{WH}_{2}$ that, similarly to our main dependent variable $\Delta W H$, is defined as actual minus contractual working time. However, while our original measure defines actual working time only by the average actual hours spent doing the main job, the alternative measure additionally includes commuting times as well as the number of working hours committed to a potential second job. ${ }^{24}$ Both of these specifications show positive and significant SMWT effects (albeit somewhat smaller than our baseline effect), further suggesting that our results do not depend on the exact definition of working time that we use to define the dependent variable.

A further worry in interpreting our main result is the question whether the extra time spent on the job as a consequence of SMWT indeed represents an increase in the worker's output and is thus desirable from the point of view of the employer, or whether the extra time is perhaps spent inefficiently. Put differently, less monitoring might induce SMWT workers to work more but less efficiently. We address this concern in Panel B of Table 6 by showing results from a series of pooled cross section and panel data regressions of our baseline specification in equation (8), where we replaced our original dependent variable $\Delta W H$ by alternative measures of

\footnotetext{
${ }^{23}$ The coefficient for contractual working hours is highly significant with the anticipated negative sign (-0.094 in the pooled OLS and -0.152 in the FE model; not displayed in Table 6).

${ }^{24}$ In order to calculate the actual working hours variable in this case, we analysed the responses to the following question: "How many hours do you spend on job, apprenticeship, and second job on a typical weekday, Saturday, and Sunday (including commuting times)?" Actual working hours are then calculated as the number of working hours on a typical workday times 5 plus the number of working hours on typical Saturdays and Sundays.
} 
individual performance. First, we use worker absenteeism measured as the number of days absent from work as an alternative measure for (inverse) worker performance (using a linear specification in columns (1) and (2) and a Tobit specification in columns (3) and (4)). ${ }^{25}$ This is a popular measure of worker performance in studies using large-scale observational survey data (e.g., Audas et al., 2004; Cornelissen et al., 2011; Ichino and Riphahn, 2005). The rationale for using this variable is that after controlling for variables that capture a worker's health (which are included among our baseline regressors), days absent from work indicate low work morale or shirking rather than sickness-related absence. The other alternative dependent variables in Panel B of Table 6 are hourly wages (measured as monthly gross wage divided by actual working hours), an ordinally scaled measure indicating an employee's worries about job security, and a binary measure indicating whether or not the respondent sees himself as someone who completes tasks effectively and efficiently. ${ }^{26}$

Importantly, SMWT has a negative effect on absenteeism, reducing the number of days absent from work by about 1.3 days per year in the FE model (column (2)) and the random effects (RE) Tobit-Mundlak model (column (4)), while holding health indicators and other control variables constant in both specifications. This suggests that SMWT indeed increases work morale, thus supporting our view that the extra time spent at work is productive. This interpretation is further corroborated by the fact that we find no negative SMWT effect on hourly wages and on self-reported efficiency (which arguably are proxies for a worker's productivity per hour spent on the job), or on worries about job security. Overall, therefore, there is little reason to believe that our SMWT effect on extra working hours measures inefficient usage of working hours rather than employee effort. This is also supported by firm-level evidence of Beckmann (2016) who finds a causal impact of the introduction of SMWT on both firm productivity and wage costs.

Finally, in Panel C of Table 6, we re-estimate our baseline model using various measures of non-standard working hours as alternative dependent variables. These include work in the evening or at night as well as work at weekends. From the respondents' information we generate

\footnotetext{
25 The original question in the SOEP questionnaires is: "How many days were you unable to work in year X due to illness?"

${ }^{26}$ There are three categories for the 'worries about job security' variable: strong worries (value 1), some worries (value 2), and no worries (value 3). The original efficiency variable is ordinally scaled between 1 and 7 . The dummy variable has been set to 1 if the ordinal variable takes the values 6 or 7 . The definitions of all additional variables applied in this section can be found in Table S5 (see the supplemental material).
} 
dummy variables indicating whether or not employees sometimes work in the evenings (after 7 p.m.), at night (after 10 p.m.), as well as on Saturdays and Sundays, and estimate linear probability models. ${ }^{27}$ According to the fixed effects estimates (column (2)), SMWT increases the probability that a worker works non-standard working hours by between $3.9 \%$ for work at night and $8.4 \%$ for evening work.

Our overall conclusion from these robustness checks is that the SMWT effect on extra work is not an artefact of the way in which our main dependent variable was defined. On the contrary, it seems to represent a real increase in working time spent productively at work. Moreover, some of the extension of working time as a result of SMWT seems to affect non-standard working hours such as evening, night, and week-end work.

\section{Does the SMWT effect vary along the distribution of extra working time?}

In some European countries (e.g., Germany and Switzerland) there is an ongoing political debate on the question whether the introduction of SMWT perhaps harms employee well-being by promoting substantial self-organized work intensification (e.g., Lehndorff, 2007; Singe and Croucher, 2003). ${ }^{28}$ Some practitioners, such as employer and employee representatives, seem to be split on this question. While employer representatives typically emphasise the positive effect that SMWT is expected to have on employees' job autonomy and work-life balance, unions often tend to oppose SMWT. One of their main arguments is that recording working hours protects workers from being exploited by the employer. Consequently, the omission of working hours registration in SMWT arrangements would pressurise workers to intensify effort in order to meet the employer's expectations. The claim is that work intensification might reach a level that could even harm the workers' physical and mental health. ${ }^{29}$ SMWT is also controversially discussed among managers, as was recently demonstrated by the cancelation of working from home (which is often a component of SMWT) at Yahoo enacted by CEO Marissa Mayer. In particular, Mrs.

\footnotetext{
${ }^{27}$ See Angrist and Pischke (2009, Section 3.4.2) for a justification of applying linear regression models to limited dependent variables.

${ }^{28}$ For the Swiss debate see, e.g., http://www.seco.admin.ch/dokumentation/publikation/00008/00022/04951/index. html?lang=de. Additionally, in Switzerland SMWT arrangements may even come into conflict with current labour legislation. For a general discussion on the impact of decentralisation practices on worker stress see, e.g., Azkenazy (2001).

${ }^{29}$ Another argument is that due to the omission of working hours registration, SMWT allows employers to deprive their employees of paying overtime premiums.
} 
Mayer raised concerns that work from home would undermine the employees' work morale (Miller and Perlroth, 2013).

However, our results from Section 4 show that neither the concerns in terms of unhealthy work intensification nor the shirking conjecture appear to be appropriate. On the contrary, we find a moderate positive effect of SMWT on employee extra effort. This moderate effort increase induced by SMWT clearly contradicts the shirking hypothesis and is presumably too small to justify the claim of unhealthy work intensification. Moreover, we find no indication for reciprocal work intensification as presumed, for example, in Kelliher and Anderson (2010).

On the other hand, given the fact that our SMWT estimate is an average effect, it may still be possible that SMWT causes employee shirking in some workplaces and work intensification in others depending on various factors, such as the culture and the nature of relationship. In order to test whether the SMWT effect varies along the distribution of extra working time, we run a fixed effects quantile regression model applying the estimation procedure introduced in Powell (2014a, 2014b). The estimation results for the SMWT effect are shown in Figure 1.

[Insert Figure 1 about here]

Figure 1 demonstrates that the point estimate for SMWT indeed varies along the distribution of extra working hours $\Delta W H$ ranging between 0.699 and 3.366 extra working hours per week. ${ }^{30}$ Furthermore, we observe a quite steady increase of the SMWT effect from lower to higher quantiles. In sum, since the estimated SMWT effects are neither negative nor excessively high, two conclusions arise from these results. First, there is no evidence for the conjecture that SMWT promotes employee shirking. This holds even at lower quantiles of the distribution of extra working hours. Second, we also do not find support for the (unhealthy) work intensification hypothesis. This conclusion might perhaps be debatable if one focusses on the SMWT effects estimated at higher quantiles. For example, the maximum SMWT effect of 3.366 extra hours per week estimated at the $90 \%$ quantile translates to about 40 extra minutes per working day that can be ascribed to the work under an SMWT regime. An amount of 40 extra minutes per day is, of course, not negligible. However, we believe that this level of extra work should be compensated by extensive decision rights of the employees to determine their own working hours. This assessment is confirmed by studies that examine the effects of SMWT and other forms of

\footnotetext{
${ }^{30}$ Apart from the SMWT coefficient at the $15 \%$ quantile, all other coefficients are highly significant.
} 
working time autonomy on stress at work or the workers' mental health (e.g., Cottini and Lucifora, 2013; Shvartsman and Beckmann, 2015). None of these studies found significant associations between working time autonomy and stress intensity or mental health problems. In fact, the results displayed in Figure 1 are consistent with our result on the complementary relationship between SMWT and intrinsic motivation, i.e., the SMWT effect increases with higher quantiles because intrinsically motivated workers are more likely to be present at higher quantiles.

\section{Conclusion}

In this paper, we examine the impact of self-managed working time (SMWT), which provides employees with autonomy over scheduling their own working hours, on employee effort. Our theoretical model shows that SMWT will lead to an overall positive effect on effort if intrinsic motivation and reciprocal behaviour dominate a possible decline of extrinsic incentives due to a loss of control. Using a large representative individual-level panel data set, the German SocioEconomic Panel (SOEP), we empirically examine the effect of SMWT on employee effort, as measured by the difference of employees' actual working time and their contractual obligation.

Without controlling for selection into SMWT based on observable and unobservable characteristics, we find a large and significant association between SMWT and extra working time, which sharply declines when accounting for observed and unobserved characteristics. Our preferred fixed effects estimates imply the following decomposition of the raw difference of five hours of extra work per week between workers with SMWT and workers with fixed working time. About one hour and 40 minutes of the initial five weekly hours of extra working time can be attributed to selection on observable individual, job or firm characteristics. Roughly another two hours can be attributed to unobserved factors, leaving an average effect of approximately 80 minutes that can be ascribed to the policy of SMWT itself. We present additional evidence that SMWT increases rather than reduces worker performance as proxied by a number of alternative measures of extra work, individual productivity, and non-standard working hours. These results justify our interpretation of the SMWT effect on extra working time as an effect on worker effort. Furthermore, we find positive SMWT effects at various quantiles along the distribution of extra working time, where effect sizes increase at higher quantiles. This additionally supports our 
previous results regarding the rejection of the shirking hypotheses, while at the same time there is no reason to believe that SMWT promotes (unhealthy) work intensification.

We conduct supplementing analyses to obtain some information about potential complementarities between SMWT, intrinsic motivation and worker reciprocity. First of all, we find that SMWT amplifies the positive effort effect of an employee's intrinsic motivation, where intrinsic motivation is measured as an employee's desire to work at least as much hours as contractually agreed, which we show to be a signal for joy at work, commitment to the job, or a high aspiration level concerning work attitude or work morale. Specifically, we find that the effect of being self-motivated while working under an SMWT arrangement is approximately 1.5 hours per week, which exceeds the effect of being self-motivated without SMWT by about 50 minutes. However, we find no complementarity between SMWT and employee reciprocity, which rules out reciprocity as a potential channel of the SMWT effect. Perhaps surprisingly, we also find no complementarity between SMWT and performance evaluations as an indicator of extrinsic motivation. This suggests that it is particularly effective to select intrinsically motivated workers into SMWT, while additional performance evaluations do not boost the effort effect of SMWT.

The main estimation strategy that we employed consists of controlling for worker-firm spell fixed effects (holding time-invariant unobserved worker and firm characteristics constant) and controlling for a large array of detailed time-varying worker and firm characteristics. We are confident that this has removed the most important endogeneity biases. This view is confirmed by an exploratory instrumental variables approach (see the supplemental material) which delivers statistically significant results that are qualitatively similar to our main results (though with wider confidence intervals). Nevertheless, it would clearly be desirable in future research to analyse our research question by conducting a field experiment, for example, exploiting a company-wide policy change towards SMWT, or (even better) implementing random assignment of SMWT. That would probably allow estimating a cleaner causal effect than is possible to estimate based on observational data. However, it should be born in mind that field experiments usually apply to specific contexts (such as specific firms or specific occupations), and therefore may have limited generalisability. We therefore believe that it is also important to conduct generalisable studies such as ours, controlling for biases as much as is possible in a large-scale observational dataset. 
The results of our study provide some important policy implications that are relevant for both management and employee representatives. While the latter may be concerned about a potential work intensification following the introduction of SMWT, managers might consider adopting SMWT (e.g., in the context of fringe benefits or work-life balance programs) and wonder whether SMWT is associated with increased employee effort or shirking. According to our empirical results, the extra effort effect induced by SMWT is positive but modest, so both employers and employees should benefit from the use of SMWT. Employers can benefit from introducing SMWT, because, on average, SMWT arrangements do not encourage employee shirking, but instead tend to elicit positive effort effects. The largest effort effect can be achieved if managers select intrinsically motivated employees for working under SMWT. On the other hand, employees should also benefit from SMWT, because the modest effort effect could probably be compensated by the increased time autonomy coming along with SMWT. Consistent with this idea is our finding that the effort increasing effect caused by SMWT is more a matter of improved employee motivation than of reciprocal work intensification.

\section{Acknowledgements}

We would like to thank two anonymous referees as well as the editors Scott J. Adams and Daiji Kawaguchi for valuable comments and suggestions. This research did not receive any specific grant from funding agencies in the public, commercial, or not-for-profit sectors. 


\section{References}

Aghion, P., Tirole, J., 1997. Formal and real authority in organizations. Journal of Political Economy 105, 1-29.

Aghion, P., Bloom, N., Van Reenen, J., 2013. Incomplete contracts and the internal organization of the firm. Journal of Law, Economics, and Organization 30, i37-i63.

Akerlof, G.A., 1982. Labor contracts as partial gift exchange. Quarterly Journal of Economics 97, 543-569.

Angrist, J.D., Pischke, J.-S., 2009. Mostly Harmless Econometrics. Princeton: Princeton University Press.

Askenazy, P., 2001. Innovative workplace practices and occupational injuries and illnesses in the United States. Economic and Industrial Democracy 22, 485-516.

Audas, R., Barmby, T., Treble, J., 2004. Luck, effort, and reward in an organizational hierarchy. Journal of Labor Economics 22, 379-395.

Baltagi, B.H., 2008. Econometric Analysis of Panel Data, 4th ed. Chichester, UK: John Wiley \& Sons.

Baron, J.N., Kreps, D.M., 1999. Strategic Human Resources. New York: John Wiley \& Sons.

Beckers, D.G.J., Kompier, M.A.J., Kecklund, G., Härmä, M., 2012. Worktime control: theoretical conceptualization, current empirical knowledge, and research agenda. Scandinavian Journal of Work, Environment \& Health 38, 291-297.

Beckmann, M., 2016. Self-managed working time and firm performance: microeconometric evidence. Mimeo.

Bell, L.A., Freeman, R.B., 2001. The incentive for working hard: explaining hours worked differences in the US and Germany. Labour Economics 8, 181-202.

Benabou, R., Tirole, J., 2006. Incentives and prosocial behaviour. American Economic Review 96, 1652-1678.

Besley, T., Ghatak, M., 2005. Competition and incentives with motivated agents. American Economic Review 95, 616-636.

Blau, P.M., 1964. Exchange and Power in Social Life. New York: John Wiley \& Sons. 
Bloom, N., Liang, J., Roberts, J., Ying, Z.J., 2015. Does working from home work? Evidence from a Chinese experiment. Quarterly Journal of Economics 130, 165-218.

Bloom, N., Van Reenen, J., 2011. Human resource management and productivity. In: Ashenfelter, O., Card, D., (Eds.). Handbook of Labor Economics, Vol. 4b. NorthHolland: Elsevier, 1697-1767.

Choe, C., Ishiguro, S., 2012. On the optimality of multi-tier hierarchies: coordination versus motivation. Journal of Law, Economics, and Organization 28, 486-517.

Cornelissen, T., Himmler, O., Koenig, T., 2011. Perceived unfairness in CEO compensation and work morale. Economics Letters 110, 45-48.

Cottini, E., Lucifora, C., 2013. Mental health and working conditions in Europe. Industrial and Labor Relations Review 66, 958-988.

Deci, E.L., Ryan, R.M., 1985. Intrinsic Motivation and Self-Determination in Human Behavior. New York: Plenum.

Deci, E.L., Ryan, R.M., 2000. The "what" and "why" of goal pursuits: human needs and the selfdetermination of behaviour. Psychological Inquiry 11, 227-268.

Delfgaauw, J., Dur, R., 2008. Incentives and workers' motivation in the public sector. Economic Journal 118, 171-191.

Dur, R., Non, A., Roelfsema, H., 2010. Reciprocity and incentive pay in the workplace. Journal of Economic Psychology 31, 676-686.

Dutcher, E.G., 2012. The effects of telecommuting on productivity: an experimental examination - the role of dull and creative tasks. Journal of Economic Behavior and Organization 84, 355-363.

Eaton, S.C., 2003. If you can use them: flexibility policies, organizational commitment, and perceived performance. Industrial Relations 42, 145-167.

Ellingsen, T., Johannesson, M., 2008. Pride and prejudice: the human side of incentive theory. American Economic Review 98, 990-1008.

Eldridge, L.P., Pabilonia, S.W., 2010. Bringing work home: implications for BLS productivity measures. Monthly Labor Review 133, 18-35. 
Falk, A., Kosfeld, M., 2006. The hidden costs of control. American Economic Review 96, 16111630.

Francois, P., 2000. 'Public service motivation' as an argument for government provision. Journal of Public Economics 78, 275-299.

Friebel, G., Schnedler, W., 2011. Team governance: empowerment or hierarchical control. Journal of Economic Behavior and Organization 78, 1-13.

Giardini, A., Kabst, R., 2008. Effects of work-family human resource practices: a longitudinal perspective. International Journal of Human Resource Management 19, 2079-2094.

Godart, O., Görg, H., Hanley, A., 2016. Trust-based work-time and innovation: evidence from firm level data. Forthcoming in: Industrial and Labor Relations Review, doi:10.1177/0019793916676259.

Golden, L., 2009. Flexible daily work schedules in U.S. jobs: formal introduction needed?. Industrial Relations 48, 27-54.

Golden, L., 2012. The effects of working time on productivity and firm performance: a research synthesis paper. International Labour Office, Conditions of Work and Employment Branch, Geneva.

Goudswaard, A., Dhondt, S., Vergeer, R., Oeij, P., 2012. Organisation of working time: implications for productivity and working conditions. European Foundation for the Improvement of Living and Working Conditions.

Heineck, G., Anger, S., 2010. The returns to cognitive abilities and personality traits in Germany. Labour Economics 17, 535-546.

Holmstrom, B., Milgrom, P., 1987. Aggregation and linearity in the provision of intertemporal incentives. Econometrica 55, 303-328.

Holmstrom, B., Milgrom, P., 1990. Regulating trade among agents. Journal of Institutional and Theoretical Economics 146, 85-105.

Holmstrom, B., Milgrom, P., 1991. Multitask principal-agent analyses: incentive contracts, asset ownership, and job design. Journal of Law, Economics, and Organization 7, 24-52.

Homans, G.C., 1958. Social behavior as exchange. American Journal of Sociology 63, 597-606. 
Ichino, A., Riphahn, R.T., 2005. The effect of employement protection on worker effort: absenteeism during and after probation. Journal of the European Economic Association 3, 120-143.

Kelliher, C., Anderson, D., 2010. Doing more with less? Flexible working practices and the intensification of work. Human Relations 63, 83-106.

Kelly, E.L., Moen, P., 2007. Rethinking the clockwork of work: why schedule control may pay off at work and at home. Advances in Developing Human Resources 9, 487-506.

Lambert, S.J., 2000. Added benefits: the link between work-life benefits and organizational citizenship behaviour. Academy of Management Journal 43, 801-815.

Lehndorff, S., 2007. Flexibility and control: new challenges for working time policy in the European Union. Labour \& Industry 17, 9-27.

Leslie, L.M., Flaherty Manchester, C., Park, T.-Y., Mehng, S.A., 2012. Flexible work practices: a source of career premiums or penalties?. Academy of Management Journal 55, 14071428.

Lyness, K.S., Gornick, J.C., Stone, P., Grotto, A.R., 2012 It's all about control: worker control over schedule and hours in cross-national context. American Sociological Review 77, 1023-1049.

Milgrom, P., Roberts, J., 1992. Economics, Organization and Management. Englewood Cliffs: Prentice Hall.

Miller, C.C., Perlroth, N., 2013. Yahoo says new policy is meant to raise morale. The New York Times, March 5, 2013, http://www.nytimes.com/2013/03/06/technology/yahoos-inoffice-policy-aims-to-bolster-morale.html?pagewanted=all\&_r=0.2013.

Moen, P., Kelly, E.L., Hill, R., 2011a. Does enhancing work-time control and flexibility reduce turnover? A naturally occurring experiment. Social Problems 58, 69-98.

Moen, P., Kelly, E.L., Tranby, E., Huang, Q., 2011b. Changing work, changing health: can real work-time flexibility promote health behaviors and well-being? Journal of Health and Social Behavior 52, 404-429. 
Murdock, K., 2002. Intrinsic motivation and optimal incentive contracts. RAND Journal of Economics 33, 650-671.

Nijp, H.H., Beckers, D.G.J., Geurts, S.A.E., Tucker, P., Kompier, M.A.J., 2012. Systematic review on the association between employee worktime control and work-non-work balance, health and well-being, and job-related outcomes. Scandinavian Journal of Work, Environment \& Health 38, 299-313.

Powell, D., 2014a. Did the economic stimulus payments of 2008 reduce labor supply?. Evidence from quantile panel data estimation. Working Papers, RAND Corporation Publications Department.

Powell, D., 2014b. Documentation for quantile regression for panel data (QRPD). Mimeo.

Shockley, K.M., Allen, T.D., 2012. Motives for flexible work arrangement use. Community, Work \& Family 15, 217-231.

Shvartsman, E., Beckmann, M., 2015. Stressed by your job: does personnel policy matter?. Journal of Applied Science Studies 135, 429-464.

Singe, I., Croucher, R., 2003. The management of trust-based working time in Germany. Personnel Review 32, 492-509.

Turban, D.B., Tan, H.H., Brown, K.G., Sheldon, K.M., 2007. Antecedents and outcomes of perceived locus of causality: an application of self-determination theory. Journal of Applied Social Psychology 37, 2376-2404.

Wagner, G.G., Frick, J.R., Schupp, J., 2007. The German Socio-Economic Panel study (SOEP): scope, evolution and enhancements. Journal of Applied Science Studies 127, 139-170. 
Table 1: Incidence of different working time arrangements

\begin{tabular}{lcccccc}
\hline \hline Working time arrangement & 2003 & 2005 & 2007 & 2009 & 2011 & Total \\
\hline Fixed daily working hours & 44.8 & 43.8 & 42.3 & 41.7 & 41.3 & 42.9 \\
Working hours fixed by employer & 22.4 & 22.0 & 22.6 & 23.6 & 21.9 & 22.5 \\
Flexitime within a working hours account & 18.9 & 19.9 & 20.3 & 20.4 & 21.8 & 20.2 \\
Working hours fixed by employee (SMWT) & 13.9 & 14.3 & 14.8 & 14.3 & 15.0 & 14.4 \\
\hline$N$ & 9,583 & 8,755 & 8,785 & 8,752 & 6,915 & 42,790 \\
\hline \hline
\end{tabular}

Note: The means are displayed in percent. $N$ is sample size.

Table 2: Actual and contractual working hours per week

\begin{tabular}{|c|c|c|c|c|c|c|c|}
\hline Working time arrangement & & 2003 & 2005 & 2007 & 2009 & 2011 & Total \\
\hline \multirow[t]{3}{*}{ Fixed daily working hours } & $W H^{a}$ & 35.8 & 35.9 & 36.5 & 35.9 & 35.9 & 36.0 \\
\hline & $W H^{c}$ & 33.6 & 33.6 & 33.8 & 33.5 & 33.3 & 33.6 \\
\hline & $\Delta W H$ & 2.2 & 2.3 & 2.7 & 2.4 & 2.6 & 2.4 \\
\hline \multirow[t]{3}{*}{ Working hours fixed by employer } & $W H^{a}$ & 37.6 & 37.9 & 37.9 & 37.6 & 38.0 & 37.8 \\
\hline & $W H^{c}$ & 33.7 & 33.7 & 33.5 & 33.3 & 33.5 & 33.5 \\
\hline & $\Delta W H$ & 3.9 & 4.2 & 4.4 & 4.3 & 4.5 & 4.3 \\
\hline \multirow[t]{3}{*}{ Flexitime within a working hours account } & $W H^{a}$ & 39.8 & 40.1 & 39.7 & 39.6 & 40.0 & 39.8 \\
\hline & $W H^{c}$ & 35.8 & 36.1 & 35.8 & 35.8 & 36.1 & 35.9 \\
\hline & $\Delta W H$ & 4.0 & 4.0 & 3.9 & 3.8 & 3.9 & 3.9 \\
\hline \multirow[t]{3}{*}{ Working hours fixed by employee (SMWT) } & $W H^{a}$ & 38.1 & 40.2 & 41.1 & 41.0 & 39.1 & 39.9 \\
\hline & $W H^{c}$ & 31.1 & 33.0 & 33.0 & 33.3 & 32.2 & 32.5 \\
\hline & $\Delta W H$ & 7.0 & 7.2 & 8.1 & 7.7 & 6.9 & 7.4 \\
\hline $\begin{array}{l}\text { Difference between SMWT and fixed daily } \\
\text { working hours }\end{array}$ & $\Delta W H^{S M}$ & 4.8 & 4.9 & 5.4 & 5.3 & 4.3 & 5.0 \\
\hline
\end{tabular}

Note: The displayed values are average weekly working hours. $W H^{a}$ is average actual working hours per week, $W H^{c}$ is contractual working hours per week and $\Delta W H=W H^{a}-W H^{c} \cdot \Delta W H^{S M}$ is the difference in $\Delta W H$ between workers with SMWT and workers with fixed daily working hours. The calculations are based on 38,312 observations. 
Table 3: Effects of self-managed working time on employee extra effort

\begin{tabular}{lcccc}
\hline Estimation strategy & OLS & OLS & Tobit ML & FE \\
\hline Self-managed working time $(S M)$ & $(1)$ & $(2)$ & $(3)$ & $(4)$ \\
& $4.987^{* * *}$ & $3.308^{* * *}$ & $2.684^{* * *}$ & $1.346^{* * *}$ \\
Employer-determined working time $(E D)$ & $1.845^{* * *}$ & $1.407^{* * *}$ & $1.465^{* * *}$ & $0.758^{* * *}$ \\
& $(0.085)$ & $(0.093)$ & $(0.080)$ & $(0.110)$ \\
Flexitime $(F T)$ & $1.479^{* * *}$ & $0.732^{* * *}$ & $1.103^{* * *}$ & $0.602^{* * *}$ \\
& $(0.078)$ & $(0.093)$ & $(0.081)$ & $(0.118)$ \\
Low / medium job autonomy & & $0.309^{* *}$ & $0.408^{* * *}$ & 0.139 \\
& & $(0.139)$ & $(0.133)$ & $(0.207)$ \\
Medium job autonomy & & $0.705^{* * *}$ & $0.918^{* * *}$ & $0.523^{* *}$ \\
& & $(0.154)$ & $(0.145)$ & $(0.232)$ \\
Medium / high job autonomy & & $1.845^{* * *}$ & $1.784^{* * *}$ & $1.039^{* * *}$ \\
& & $(0.202)$ & $(0.173)$ & $(0.272)$ \\
High job autonomy & & $3.501^{* * *}$ & $2.688^{* * *}$ & $1.282^{* * *}$ \\
& & $(0.470)$ & $(0.322)$ & $(0.463)$ \\
Control variables & No & Yes & Yes & Yes \\
Industry dummies & No & Yes & Yes & Yes \\
Firm size dummies & No & Yes & Yes & No \\
Time dummies & No & Yes & Yes & Yes \\
Occupation dummies & No & Yes & Yes & Yes \\
Worker-firm spell fixed effects & No & No & No & Yes \\
\hline$R^{2} /$ Pseudo- $R^{2} / R^{2}$-within & 0.078 & 0.305 & 0.073 & 0.102 \\
$N$ & 38,312 & 30,699 & 30,699 & 31,522 \\
\hline \hline
\end{tabular}

Note: $* p<0.1 ; * * p<0.05$; *** $p<0.01$. The dependent variable is $\Delta W H$. The values in parentheses represent robust standard errors clustered at the individual level. The specifications in columns (2) - (4) contain a set of covariates described in Table S5, where the corresponding estimates are displayed in Table S4 (see the supplemental material). The Tobit ML estimates displayed in column (3) represent marginal effects. 
Table 4: Does $I M$ measure intrinsic motivation, work load, or even extrinsic motivation?

\begin{tabular}{|c|c|c|c|}
\hline Indicators & Explanatory variables & $\begin{array}{l}\text { Effect on } \\
I M(\mathrm{OLS})\end{array}$ & $\begin{array}{c}\text { Available } \\
\text { panel waves }\end{array}$ \\
\hline \multirow[t]{7}{*}{$\begin{array}{l}\text { Intrinsic } \\
\text { motivation }\end{array}$} & $\begin{array}{l}\text { Job satisfaction: Self-reported level of job } \\
\text { satisfaction }\end{array}$ & $\begin{array}{l}0.026 * * * \\
(0.002)\end{array}$ & 2003-2011 \\
\hline & $\begin{array}{l}\text { Sacrifice: "Those closest to me say I sacrifice myself } \\
\text { too much for my job." }\end{array}$ & $\begin{array}{l}0.044 * * * \\
(0.011)\end{array}$ & 2006,2011 \\
\hline & $\begin{array}{l}\text { Unpaid overtime: percentage of unpaid overtime } \\
\text { work in total overtime hours (last month) }\end{array}$ & $\begin{array}{l}0.027 * * * \\
(0.010)\end{array}$ & 2003-2011 \\
\hline & $\begin{array}{l}\text { Hard-working: "I see myself as someone who does } \\
\text { not tend to be lazy." }\end{array}$ & $\begin{array}{l}0.057 * * * \\
(0.016)\end{array}$ & 2005,2009 \\
\hline & $\begin{array}{l}\text { Thorough: "I see myself as someone who does a } \\
\text { thorough job." }\end{array}$ & $\begin{array}{l}0.040 * * * \\
(0.015)\end{array}$ & 2005,2009 \\
\hline & $\begin{array}{l}\text { Task efficiency: "I see myself as someone who } \\
\text { accomplishes tasks effectively and efficiently." }\end{array}$ & $\begin{array}{l}0.039 * * * \\
(0.012)\end{array}$ & 2005,2009 \\
\hline & Joy at work: "I really enjoy my work." & $\begin{array}{l}0.091 * * * \\
(0.022)\end{array}$ & 2008 \\
\hline \multirow[t]{2}{*}{ Work load } & $\begin{array}{l}\text { Work strain: "The amount of work has increased } \\
\text { steadily over the last two years." }\end{array}$ & $\begin{array}{l}-0.020 * \\
(0.011)\end{array}$ & 2006,2011 \\
\hline & $\begin{array}{l}\text { Time pressure: "Because of the high volume of work } \\
\text { there is often high time pressure." }\end{array}$ & $\begin{array}{c}-0.025 * * \\
(0.011)\end{array}$ & 2006, 2011 \\
\hline \multirow[t]{3}{*}{$\begin{array}{l}\text { Extrinsic } \\
\text { motivation }\end{array}$} & $\begin{array}{l}\text { Paid overtime: percentage of paid overtime work in } \\
\text { total overtime hours (last month) }\end{array}$ & $\begin{array}{l}-0.027 * * * \\
(0.010)\end{array}$ & 2003-2011 \\
\hline & $\begin{array}{l}\text { Expected promotion: self-reported probability of } \\
\text { receiving a promotion at the current place of } \\
\text { employment }(\%)\end{array}$ & $\begin{array}{c}0.000 \\
(0.008)\end{array}$ & $\begin{array}{l}2003,2005 \\
2007,2009\end{array}$ \\
\hline & $\begin{array}{l}\text { Expected pay rise: self-reported probability of } \\
\text { receiving an individual pay rise that goes beyond the } \\
\text { collectively negotiated pay rate increase }(\%)\end{array}$ & $\begin{array}{l}-0.005 \\
(0.009)\end{array}$ & $\begin{array}{l}2003,2005 \\
2007,2009\end{array}$ \\
\hline
\end{tabular}

Note: $* p<0.1$; ** $p<0.05$; *** $p<0.01$. The dependent variable is $I M$. The values in parentheses represent robust standard errors clustered at the individual level. Job satisfaction is an ordinally scaled variable ranging between 0 (completely unsatisfied) and 10 (completely satisfied). The variables explained in italic font are dummy variables on an employee's approval to the respective statement. The sample is restricted to full-time employees. All specifications include the same control variables as the regression model displayed in Table 3, column (2). 
Table 5: Complementarity analysis

\begin{tabular}{|c|c|c|c|c|}
\hline Estimation strategy & FE & FE & FE & FE \\
\hline & (1) & (2) & (3) & (4) \\
\hline Self-managed working time ( $S M$ ) & $\begin{array}{c}1.289 * * * \\
(0.190)\end{array}$ & $\begin{array}{c}1.657 * * * \\
(0.223)\end{array}$ & $\begin{array}{c}1.053 * * * \\
(0.355)\end{array}$ & $\begin{array}{c}1.049 * * * \\
(0.354)\end{array}$ \\
\hline Intrinsic motivation ( $I M)$ & $\begin{array}{c}0.706 * * * \\
(0.091)\end{array}$ & $\begin{array}{c}0.759 * * * \\
(0.099)\end{array}$ & $\begin{array}{c}0.687 * * * \\
(0.100)\end{array}$ & $\begin{array}{c}0.689 * * * \\
(0.100)\end{array}$ \\
\hline Positive reciprocity $(R)$ & $\begin{array}{l}0.164 * \\
(0.096)\end{array}$ & $\begin{array}{l}0.188^{*} \\
(0.115)\end{array}$ & $\begin{array}{c}0.177 \\
(0.114)\end{array}$ & $\begin{array}{c}0.176 \\
(0.114)\end{array}$ \\
\hline Performance evaluation, overall ( $P E)$ & $\begin{array}{l}-0.0154 \\
(0.101)\end{array}$ & $\begin{array}{l}-0.053 \\
(0.120)\end{array}$ & $\begin{array}{l}-0.047 \\
(0.120)\end{array}$ & \\
\hline $\begin{array}{l}\text { Performance evaluation without consequences } \\
\left(P E_{1}\right)\end{array}$ & & & & $\begin{array}{l}-0.276^{*} \\
(0.159)\end{array}$ \\
\hline $\begin{array}{l}\text { Performance evaluation with consequences } \\
\left(P E_{2}\right)\end{array}$ & & & & $\begin{array}{c}0.114 \\
(0.143)\end{array}$ \\
\hline Interaction $(I M \times S M)$ & & & $\begin{array}{c}0.816^{* *} \\
(0.344)\end{array}$ & $\begin{array}{c}0.824 * * \\
(0.343)\end{array}$ \\
\hline Interaction $(R \times S M)$ & & & $\begin{array}{c}0.088 \\
(0.335)\end{array}$ & $\begin{array}{c}0.095 \\
(0.335)\end{array}$ \\
\hline Interaction $(P E \times S M)$ & & & $\begin{array}{c}-0.062 \\
(0.354)\end{array}$ & \\
\hline Interaction $\left(P E_{1} \times S M\right)$ & & & & $\begin{array}{l}-0.517 \\
(0.624)\end{array}$ \\
\hline Interaction $\left(P E_{2} \times S M\right)$ & & & & $\begin{array}{c}0.010 \\
(0.373)\end{array}$ \\
\hline$R^{2}$-within & 0.115 & 0.129 & 0.130 & 0.130 \\
\hline$N$ & 26,387 & 20,565 & 20,565 & 20,565 \\
\hline
\end{tabular}

Note: $* p<0.1 ; * * p<0.05 ; * * * p<0.01$. The dependent variable is $\Delta W H$. The values in parentheses represent robust standard errors clustered at the individual level. Specification (1) refers to the full sample, whereas specifications (2)-(4) are restricted to a sample of full-time employees. The specifications extend equations (8) and (9) by the explanatory variables and interaction terms displayed. All estimation models additionally contain the same control variables as the regression models displayed in Table 3, column (4). 
Table 6: The SMWT effect for alternative performance measures

\begin{tabular}{ccccc}
\hline \hline Estimation strategy & $\begin{array}{c}\text { Pooled OLS / } \\
\text { ordered logit }\end{array}$ & $\begin{array}{c}\text { Linear FE / or- } \\
\text { dered logit FE }\end{array}$ & Tobit ML & $\begin{array}{c}\text { RE Tobit- } \\
\text { Mundlak }\end{array}$ \\
\hline$(1)$ & $(2)$ & (3) & (4)
\end{tabular}

Panel A: Alternative measures of extra work

$\begin{array}{lcc}\Delta W H & 3.221 * * * & 1.296 * * * \\ & (0.177) & (0.179) \\ \text { Overtime last month } & 1.609 * * * & 0.691 * * * \\ & (0.113) & (0.130) \\ \Delta W H_{2} & 1.444 * * * & 0.770 * * * \\ & (0.239) & (0.285)\end{array}$

Panel B: Alternative productivity measures

Absenteeism

$-1.224 * * *$

(0.424)

Worries about job security

$0.264 * * *$

(0.048)

Hourly wage

$1.271 * * *$

(0.218)

Task efficiency

$-0.006$

(0.016)
$-1.306^{*}$

$(0.788)$

0.045

(0.094)

0.217

(0.195)

$-0.014$

(0.039)

Panel C: Non-standard working hours

Work in the evening

Work at night

Work on Saturday

Work on Sunday

$$
0.218 * * *
$$$$
\text { (0.012) }
$$

$0.093 * * *$

(0.011)

$$
0.146 * * *
$$

$$
0.134 * * *
$$

(0.013)
$0.084 * * *$

(0.017)

$0.039 * *$

(0.015)

$0.068 * * *$

(0.016)

$0.040 * *$

(0.017)

Note: $* p<0.1 ; * * p<0.05$; ${ }^{* * *} p<0.01$. The values in parentheses represent robust standard errors clustered at the individual level. The specifications include the same control variables as the corresponding regression models displayed in Table 3. The $\Delta W H$ model additionally controls for contractual working hours. In the 'Hourly wage'equation, the control variables 'gross monthly wage' and 'satisfaction with household income' are excluded from the set of control variables. In the 'Worries about job security'-model, the depended variable is ordinally scaled and the dummy variables 'strong worries about job security' and 'some worries about job security' are excluded from the set of control variables. The Tobit ML and RE Tobit-Mundlak estimates represent marginal effects. 
Figure 1: The effect of $S M$ on $\Delta W H$ resulting from a fixed effects quantile regression

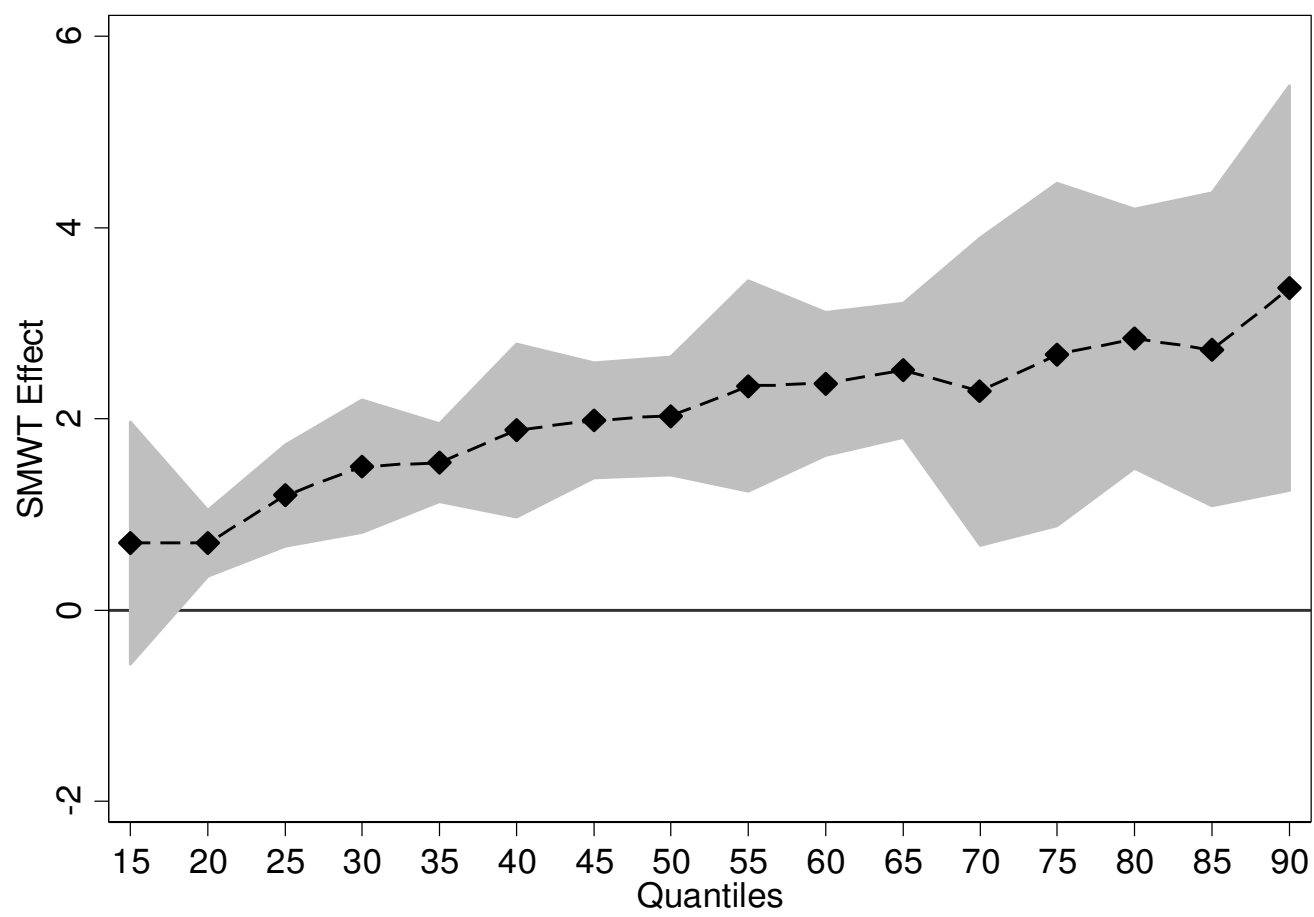

Note: The squares represent the point estimates for SMWT measured at different quantiles of the distribution of extra working hours per week. The grey-shaded area represents the respective confidence intervals at the $95 \%$ significance level. The quantile regression model includes the same control variables as the FE regression model displayed in Table 3, column (4). 


\section{Supplemental material (not intended to be published)}

Section S1 examines whether our FE estimations discussed in Section 4.2 suffer from potentially remaining endogeneity biases caused by unobserved time-varying heterogeneity. Here, our estimation strategies are introduced and the results are discussed. Section S2 provides additional information that is not included in the paper. First, a correlation matrix for major dependent and independent variables is displayed in Table S3. Second, Table S4 refers to Table 3 containing the OLS and FE estimates of the complete estimation models. Finally, Section S3 entails the description and the descriptive statistics of the entire set of variables used in this study.

\section{S1. Instrumental variables approaches}

After controlling for worker-firm spell fixed effects according to equation (8), there may be an additional bias due to a potential correlation between $S M$ and $u_{i t}$, which may result from the omission of time-varying characteristics that drive selection into a particular work time regime, or from reverse causality. In the latter case, an employee's decision in favour of SMWT may depend on his actual working hours. Moreover, employees may sort into different working time regimes based on time-varying unobserved characteristics, which also affect their effort choices. Examples include personality traits that may change over time, or unobserved changes to an individual's life circumstances. If not addressed, both reverse causality and selection based on time-varying unobservable characteristics might cause estimation biases.

To address these issues, we combine equation (8) with instrumental variables (IV) approaches. Specifically, we use two related two-step identification strategies, where the first is based on predictor substitution and the second relies on residual inclusion. Both approaches require the estimation of reduced form equations for each of the three flexible working time regimes in the first stage. For the first approach these equations are

$$
\begin{aligned}
& S M_{i t}=\varphi_{11} E D_{i t}+\varphi_{12} F T_{i t}+J A_{i t} \rho_{1}+X_{i t} \vartheta_{1}+Z_{1 i t-2} \omega_{11}+\omega_{12} Z_{2 i t}+v_{i, j(i t)}^{S M}+\varepsilon_{1 i t} \\
& E D_{i t}=\varphi_{21} S M_{i t}+\varphi_{22} F T_{i t}+J A_{i t} \rho_{2}+X_{i t} \vartheta_{2}+Z_{1 i t-2} \omega_{21}+\omega_{22} Z_{2 i t}+v_{i, j(i t)}^{E D}+\varepsilon_{2 i t} \\
& F T_{i t}=\varphi_{31} S M_{i t}+\varphi_{32} E D_{i t}+J A_{i t} \rho_{3}+X_{i t} \vartheta_{3}+Z_{1 i t-2} \omega_{31}+\omega_{32} Z_{2 i t}+v_{i, j(i t)}^{F T}+\varepsilon_{3 i t} .
\end{aligned}
$$


Here, $v_{i, j(i t)}$ and $\varepsilon_{i t}$ represent the worker-firm spell fixed effects and the idiosyncratic error terms. The vector $X$ contains the same control variables as in equation (8). Altogether, $Z_{1}$ and $Z_{2}$ comprise four identifying instrumental variables that are excluded from the primary equation (8). For instrumental variables to be valid, they must be relevant, i.e., significant predictors of the working time arrangements in the first stage, and exogenous, i.e., uncorrelated with the idiosyncratic error term $u_{i t}$ in equation (8).

Our first three exclusion restrictions, included in $Z_{1}$, follow a standard procedure of IV estimations with panel data (e.g., Fernandez-Val and Vella, 2011; Vella and Verbeek, 1998). Specifically, we instrument each of the working hours arrangements with its corresponding lagged variable, i.e., $S M_{i t}$ is instrumented by $S M_{i t-2}, E D_{i t}$ is instrumented by $E D_{i t-2}$, and $F T_{i t}$ is instrumented by $F T_{i t-2}$. These instruments are relevant, because a worker's past choices are likely to affect his current choice. At first glance, it appears natural that the experience of previous work under a certain working time regime increases the likelihood of future work under that regime; therefore, we would expect positive coefficients $\omega_{j 1},(j=1,2,3)$, on the corresponding lagged working time regime variables. Note, however, that in a fixed effects within-estimation also negative coefficients on the lagged working time regime variables can occur if changes between regimes occur relatively frequent and the observation period is relatively short. As our panel is relatively short and changes between working time regimes may be caused by a number of events such as employer changes, promotions, relocations or management policy changes, negative signs of the coefficients on the lagged variables would not be surprising. With respect to the exogeneity requirement, we have to assume that a worker's working time regime in the past (lagged by two periods) has no direct effect on a worker's current work effort; i.e., that it is uncorrelated with the idiosyncratic error $u_{i t}$ in equation (8). In our application, this assumption seems credible, the more so as it only needs to hold conditional on our large set of covariates, which includes the contemporary working time regime, a large set of observed characteristics, and the worker's unobserved time-constant propensity to provide extra effort while employed at a particular firm (the worker-firm spell fixed effect). After holding all these factors constant, it is hard to see how the lagged working time regime could have a direct effect on the worker's current effort. 
As a further instrument for our focus variable, $S M_{i t}, Z_{2}$ represents the share of workers with SMWT among all workers in the same occupational status group, firm size category, sector, and region. ${ }^{31}$ This group-specific mean is positively correlated with the SMWT dummy SM by construction and should consequently be negatively correlated with the remaining working hours arrangement dummies $E D$ and $F T$. On the other hand, there is no reason to expect that the average demand for SMWT employees within each of these cells has an influence on an employee's propensity to provide extra effort in any other way than through its effect on the individual choice of SMWT. ${ }^{32}$ This should especially hold true, because we group the observations mainly according to firm characteristics rather than employee characteristics.

In our first approach, we estimate the parameters of the triangular four-equation structure (8), (S1)-(S3) by the two-stage least squares (2SLS) within estimator, where at the second stage $S M, E D$ and $F T$ in the primary equation (8) are replaced by their predicted values. We refer to this estimator as the fixed effects instrumental variables estimator (FEIV). Since the model (8), (S1)-(S3) is overidentified with four instruments for three endogenous explanatory variables, we can test the exogeneity of the overidentifying restrictions, conditional on the validity of at least as many instruments as are required for exact identification.

The 2SLS approach has the strength that it allows the inclusion of fixed effects, because the first stages are estimated as linear probability models. It has the drawback, however, that the binary nature of the endogenous regressors is not explicitly accounted for. We therefore implement a second IV approach to address this issue by estimating the first-stage equations (S1)-(S3) as probit models. Since the fixed effects probit model leads to inconsistent parameter estimates (e.g., Baltagi, 2008), we estimate random effects probit models, but proxy for timeconstant firm-specific unobserved worker heterogeneity that may be correlated with the error term by additionally including the person-firm mean values of all the time-varying covariates of (S1), (S2), and (S3), respectively. This proceeding is also known as Mundlak's approach (e.g., Greene, 2008). The first-stage equations (S1)-(S3) can then be written as

\footnotetext{
${ }^{31}$ There are 12 groups of occupational status (6 hierarchies within blue-collar jobs, and 6 hierarchies within whitecollar jobs), four firm size classes, 10 industries and the 16 federal states of Germany. Cells with just one observation do not provide real means and are therefore merged. By proceeding in this way, we prevent the instrument for these observations being identical to the endogenous SMWT variable and thus avoid potential endogeneity of the instrument.

32 The idea to use group-specific means as exclusion restrictions is not unusual and has been applied, for example, in Woessmann and West (2006).
} 
$D_{i t}^{*}=W_{i t}^{D} \eta_{1}^{D}+\overline{W_{i, j(i t)}^{D}} \eta_{2}^{D}+\theta_{i, j(i t)}^{D}+\varepsilon_{i t}^{D}$

$D_{i t}= \begin{cases}1 & \text { if } D_{i t}^{*}>0 \\ 0 & \text { otherwise }\end{cases}$

where $D$ represents $S M, E D$ or $F T$, respectively. Here, $D_{i t}^{*}$ denotes the latent propensity to choose working time regime $D_{i t}$, and $\varepsilon_{i t}^{D}$ is a normally distributed error term. The vector $W^{D}$ includes each of the right-hand-side variables of equations (S1), (S2), and (S3), while $\overline{W_{i, j(i t)}^{D}}$ contains the person-firm mean values of all time-varying covariates of (S1), (S2), and (S3). Finally, $\theta_{i, j(i t)}^{D}$ is that part of the original unobserved effect $v_{i, j(i t)}^{D}$ which remains after controlling for the person-firm means of the time-varying covariates, i.e., $\theta_{i, j(i t)}^{D}=v_{i, j(i t)}^{D}-\overline{W_{i, j(i t)}^{D}} \eta_{2}^{D}$. Mundlak's approach relies on the assumption that after controlling for the person-firm mean values, $\theta_{i, j(i t)}^{D}$ is uncorrelated with the original regressors in $W^{D}$ and can hence be treated as a random effect.

From the random effects probit estimates of (S4) and (S5), we extract the generalised residuals $s_{i t}^{D}=\left(D_{i t}-\Phi_{i t}\right) \phi_{i t} /\left[\Phi_{i t}\left(1-\Phi_{i t}\right)\right]$, where $\phi_{i t}$ and $\Phi_{i t}$ denote the PDF and CDF of the standard normal distribution evaluated at $W_{i t}^{D} \eta_{1}^{D}+\overline{W_{i, j(i t)}^{D}} \eta_{2}^{D}+\theta_{i, j(i t)}^{D}$. In the second stage, these generalised residuals are added as correction terms to equation (8) in order to control for remaining time-varying unobserved heterogeneity, i.e.,

$$
\Delta W H_{i t}=\alpha_{1} S M_{i t}+\alpha_{2} E D_{i t}+\alpha_{3} F T_{i t}+J A_{i t} \lambda+X_{i t} \beta+\tau_{1} s_{i t}^{S M}+\tau_{2} s_{i t}^{E D}+\tau_{3} s_{i t}^{F T}+\mu_{i, j(i t)}+u_{i t}
$$

Intuitively, the generalised residuals embody time-varying characteristics that drive the selection into the working time regimes, and explicitly controlling for them in the second stage removes the endogeneity bias from the coefficients of the working time regime variables. Just as for equation (8), equation (S6) is estimated by the fixed effects estimator. ${ }^{33} \mathrm{We}$ refer to this second approach as the endogeneity-corrected fixed effects estimator (ECFE).

\footnotetext{
${ }^{33}$ See Fernandez-Val and Vella (2011) for a similar two-step estimation strategy.
} 
The coefficients resulting from our FEIV estimation of equations (8), (S1)-(S3) and our ECFE estimator according to (S6) can be found in Table S1. It can be asserted that the parameter estimates are in line with our FE estimates. According to both the FEIV and the ECFE model the point estimate is approximately 1.5 hours (statistically significant at the $1 \%$ level).

Table S1: Effects of self-managed working time on employee extra effort

\begin{tabular}{|c|c|c|c|c|}
\hline \multirow{3}{*}{$\begin{array}{l}\text { Estimation strategy } \\
\text { Self-managed working time ( } S M \text { ) }\end{array}$} & \multirow{2}{*}{\multicolumn{2}{|c|}{$\frac{\text { FEIV }}{(1)}$}} & \multirow{2}{*}{\multicolumn{2}{|c|}{$\frac{\text { ECFE }}{(2)}$}} \\
\hline & & & & \\
\hline & \multirow{2}{*}{$\begin{array}{c}1.587 * * * \\
0.527\end{array}$} & \multirow{2}{*}{$\begin{array}{l}(0.514) \\
(0.577)\end{array}$} & \multirow{2}{*}{$\begin{array}{l}1.557 * * * \\
0.896 * * *\end{array}$} & \multirow{2}{*}{$\begin{array}{l}(0.310) \\
(0.241)\end{array}$} \\
\hline Employer-determined working time ( $E D$ ) & & & & \\
\hline Flexitime $(F T)$ & $1.399 *$ & $(0.722)$ & $0.560 * *$ & $(0.244)$ \\
\hline Correction term $s^{S M}$ & & & -0.405 & $(0.333)$ \\
\hline Correction term $s^{E D}$ & & & -0.173 & $(0.170)$ \\
\hline Correction term $s^{F T}$ & & & 0.130 & $(0.197)$ \\
\hline Endogeneity test ( $p$-value) & \multicolumn{2}{|c|}{0.659} & \multicolumn{2}{|c|}{0.258} \\
\hline \multicolumn{5}{|l|}{ Test on instrument relevance (test statistic) } \\
\hline$S M$ equation & \multicolumn{2}{|c|}{$610.3 * * *$} & \multicolumn{2}{|c|}{$424.6 * * *$} \\
\hline$E D$ equation & \multicolumn{2}{|c|}{$105.8 * * *$} & \multicolumn{2}{|c|}{$305.0 * * *$} \\
\hline$F T$ equation & \multicolumn{2}{|c|}{$133.9 * * *$} & \multicolumn{2}{|c|}{$373.1 * * *$} \\
\hline Hansen $J$-test ( $p$-value) & \multicolumn{2}{|c|}{0.366} & & \\
\hline$R^{2}$-within & \multicolumn{2}{|c|}{0.019} & \multicolumn{2}{|c|}{0.130} \\
\hline$N$ & \multicolumn{2}{|c|}{19,832} & \multicolumn{2}{|c|}{19,495} \\
\hline
\end{tabular}

Note: $* p<0.1 ; * * p<0.05$; *** $p<0.01$. The dependent variable is $\Delta W H$. The values in parentheses represent robust standard errors clustered at the individual level. The endogeneity test for the FEIV model is a $C$-test, while the endogeneity test for the ECFE model is an $F$-test on $\tau_{1}=\tau_{2}=\tau_{3}=0$ in (S6). Analogously, the test on instrument relevance for the FEIV (ECFE) model is an $F$-test ( $\chi^{2}$-test). The Hansen $J$-test is a test on overidentifying exclusion restrictions. The specifications contain a set of covariates described in Table S5. The specifications also include occupation dummies, industry dummies, time dummies, and worker-firm spell fixed effects.

Table S1 also includes information about the validity of the exclusion restrictions applied in the FEIV and the ECFE approach. First, relevance of the instruments is indicated by $F$ - or $\chi^{2}$ tests on joint significance in the respective first-stage regressions. Each of the test statistics by far 
exceeds the rule-of-thumb value of 10, indicating strong instruments. Instrument relevance is additionally confirmed by the corresponding parameter estimates of the first-stage equations, which are displayed in Table S2. In each of the first-stage equations both the respective lagged working time variable and the group-specific mean variable are significant at the $5 \%$ or $1 \%$ level, respectively. The group-specific mean variable exhibits the expected positive sign in the $S M$ equations and a likewise unsurprising negative sign in the $E D$ and $F T$ equations. Moreover, all lagged working time variables exhibit a negative sign in the corresponding reduced form equation. Finally, Hansen's $J$-test documents that the overidentification restrictions can be considered as exogenous $(p=0.366) .{ }^{34}$ All in all, therefore, the diagnostic tests support the validity of the overidentifying restrictions and thus emphasise the confidence in our FEIV and ECFE approaches.

Note, however, that neither the $C$-test for endogeneity nor an $F$-test on joint significance of the endogeneity correction terms $s^{S M}, s^{E D}$ and $s^{F T}$ in equation (S6), i.e., $\tau_{1}=\tau_{2}=\tau_{3}=0$, rejects the null hypothesis of exogenous working time arrangement dummies ( $p=0.659$ or $p=0.258$, respectively). This indicates that the FE estimates displayed in Table 3 can already be interpreted as causal, and that there is no necessity to additionally account for unobserved timevarying heterogeneity. As a result, the FE, FEIV and ECFE models all provide consistent estimates for the SMWT effect, where the FE model is the most efficient of the three models, producing the smallest standard errors. Therefore, the FE model is our preferred model, but its results are confirmed by the FEIV and ECFE models. ${ }^{35}$

\footnotetext{
${ }^{34} \mathrm{We}$ conducted additional tests with regard to the exogeneity assumption of our exclusion restrictions. Specifically, we ran FEIV regressions, where only three of the four instrumental variables served as exclusion restrictions, while the remaining instrument was added to the vector of control variables in the primary equation. A simple $t$-test on significance of the estimated coefficient then provides information in terms of the exogeneity assumption of this particular instrument. Each of our instruments proved to be insignificant in the primary equation which is consistent with the result of Hansen's $J$-test of overidentification. Furthermore, we simply added the instruments to equation (8) in order to test the exogeneity assumption. Neither of the instruments turned out to be significant in this specification.

${ }^{35}$ Another way to verify that the FEIV and ECFE models confirm the estimates of the FE model is to note that its SMWT effect of 1.346 hours lies within the 95\% confidence intervals for the SMWT effect resulting from the FEIV and ECFE models.
} 
Table S2: First-stage estimates of the exclusion restrictions according to (S1)-(S3)

\begin{tabular}{lcccccc}
\hline Estimation strategy & \multicolumn{3}{c}{ FEIV } & \multicolumn{3}{c}{ ECFE } \\
\hline $\begin{array}{l}\text { Explanatory variable to } \\
\text { be instrumented }\end{array}$ & $S M$ & $E D$ & $F T$ & $S M$ & $E D$ & $F T$ \\
\hline$S M_{t-2}$ & $-0.163^{* * *}$ & -0.002 & -0.010 & $-1.192^{* * *}$ & 0.149 & -0.084 \\
& $(0.014)$ & $(0.015)$ & $(0.016)$ & $(0.188)$ & $(0.108)$ & $(0.134)$ \\
$E D_{t-2}$ & 0.003 & $-0.231^{* * *}$ & $0.016^{* *}$ & 0.263 & $-0.940^{* * *}$ & 0.091 \\
& $(0.005)$ & $(0.013)$ & $(0.008)$ & $(0.193)$ & $(0.068)$ & $(0.116)$ \\
$F T_{t-2}$ & -0.013 & 0.005 & $-0.182^{* * *}$ & 0.081 & 0.050 & $-0.968^{* * *}$ \\
Group-specific mean & $(0.008)$ & $(0.012)$ & $(0.015)$ & $(0.204)$ & $(0.106)$ & $(0.107)$ \\
for employees with & $0.707^{* * *}$ & $-0.142^{* * *}$ & $-0.340^{* * *}$ & $5.065^{* * *}$ & $-1.514^{* * * *}$ & $-2.501 * * *$ \\
SMWT & $(0.016)$ & $(0.017)$ & $(0.020)$ & $(0.265)$ & $(0.165)$ & $(0.155)$ \\
\hline \hline
\end{tabular}

Note: $* p<0.1$;** $p<0.05$; *** $p<0.01$. The values in parentheses represent robust standard errors clustered at the individual level. The same sets of control variables as in Table S1 are included, but not reported to save space.

\section{S2. Correlation matrix and additional estimation results}

Table S3: Correlation matrix

\begin{tabular}{|l|c|c|c|c|c|c|c|c|c|}
\hline & $\Delta W H$ & $S M$ & $E D$ & $F T$ & $F W T$ & $I M$ & $R$ & $P E$ & AUTONO \\
\hline$\Delta W H$ & 1 & & & & & & & & \\
\hline$S M$ & $0.239^{*}$ & 1 & & & & & & & \\
\hline$E D$ & $0.056^{*}$ & $-0.183^{*}$ & 1 & & & & & & \\
\hline$F T$ & $0.021^{*}$ & $-0.185^{*}$ & $-0.278^{*}$ & 1 & & & & & \\
\hline$F W T$ & $-0.213^{*}$ & $-0.320^{*}$ & $-0.481^{*}$ & $-0.486^{*}$ & 1 & & & & \\
\hline$I M$ & $0.060^{*}$ & $0.038^{*}$ & $0.026^{*}$ & $-0.057^{*}$ & 0.003 & 1 & & & \\
\hline$R$ & $0.038^{*}$ & 0.005 & $0.031^{*}$ & $-0.037^{*}$ & 0.001 & 0.009 & 1 & & \\
\hline$P E$ & $0.081^{*}$ & $0.029^{*}$ & $-0.056^{*}$ & $0.224^{*}$ & $-0.16^{*}$ & $-0.015^{*}$ & -0.005 & 1 & \\
\hline AUTONO & $0.267^{*}$ & $0.234^{*}$ & $-0.124^{*}$ & $0.291^{*}$ & $-0.285^{*}$ & $-0.081^{*}$ & $-0.011^{*}$ & $0.177^{*}$ & 1 \\
\hline
\end{tabular}

Note: $* p<0.05$. FWT indicates the fixed working time regime. All other variable names are introduced in the paper (see also Table S5 for a description of the variables). 
Table S4: OLS and FE estimates for the complete model specifications of Table 3

\begin{tabular}{|c|c|c|c|c|}
\hline \multirow{3}{*}{$\begin{array}{l}\text { Estimation strategy } \\
\text { Self-managed working time ( } S M \text { ) }\end{array}$} & \multirow{2}{*}{\multicolumn{2}{|c|}{$\frac{\text { OLS }}{(2)}$}} & \multirow{2}{*}{\multicolumn{2}{|c|}{$\begin{array}{l}\mathrm{FE} \\
(4) \\
\end{array}$}} \\
\hline & & & & \\
\hline & $3.308 * * *$ & $(0.177)$ & $1.346 * * *$ & $(0.179)$ \\
\hline Employer-determined working time $(E D)$ & $1.407 * * *$ & $(0.093)$ & $0.758^{* * *}$ & $(0.110)$ \\
\hline Flexitime $(F T)$ & $0.732 * * *$ & $(0.093)$ & $0.602^{* * * *}$ & $(0.118)$ \\
\hline Low / medium job autonomy & $0.309^{* *}$ & $(0.139)$ & 0.139 & $(0.207)$ \\
\hline Medium job autonomy & $0.705^{* * *}$ & $(0.154)$ & $0.523^{* *}$ & $(0.232)$ \\
\hline Medium / high job autonomy & $1.845^{* * *}$ & $(0.202)$ & $1.039 * * *$ & $(0.272)$ \\
\hline High job autonomy & $3.501 * * *$ & $(0.470)$ & $1.282 * * *$ & $(0.463)$ \\
\hline Monthly gross wage & $0.728 * * *$ & $(0.052)$ & $0.361 * * *$ & $(0.082)$ \\
\hline Job satisfaction & $-0.074 * * *$ & $(0.019)$ & $-0.071 * * *$ & $(0.022)$ \\
\hline Satisfaction with household income & $-0.078^{* * *}$ & $(0.019)$ & 0.006 & $(0.026)$ \\
\hline Living with partner & -0.002 & $(0.098)$ & $-0.272 * *$ & $(0.134)$ \\
\hline Children aged under 16 & $-0.402 * * *$ & $(0.080)$ & $-0.296 * * *$ & $(0.109)$ \\
\hline Full-time employed & $0.201 *$ & $(0.117)$ & -0.180 & $(0.177)$ \\
\hline Fixed-term contract & 0.046 & $(0.138)$ & -0.180 & $(0.203)$ \\
\hline Employer change & -0.012 & $(0.132)$ & 0.117 & $(0.216)$ \\
\hline Male & $0.785 * * *$ & $(0.117)$ & & \\
\hline Foreign nationality & $-0.253^{*}$ & $(0.141)$ & & \\
\hline Job tenure & $-0.065^{* * *}$ & $(0.014)$ & -0.025 & $(0.047)$ \\
\hline Job tenure squared / 100 & $0.092^{* *}$ & $(0.037)$ & 0.054 & $(0.070)$ \\
\hline Schooling & $-0.061 * * *$ & $(0.023)$ & & \\
\hline Full-time experience & -0.020 & $(0.013)$ & $0.200^{*}$ & $(0.103)$ \\
\hline Full-time experience squared / 100 & -0.008 & $(0.033)$ & $-0.130 *$ & $(0.075)$ \\
\hline Part-time experience & -0.030 & $(0.018)$ & $0.197 *$ & $(0.105)$ \\
\hline Part-time experience squared / 100 & 0.095 & $(0.069)$ & 0.074 & $(0.151)$ \\
\hline Unemployment experience & -0.006 & $(0.046)$ & 0.440 & $(0.446)$ \\
\hline Unemployment experience squared / 100 & -0.231 & $(0.314)$ & -2.193 & $(3.738)$ \\
\hline Hobbies and other leisure activities & $-0.273 * * *$ & $(0.024)$ & $-0.129 * * *$ & $(0.031)$ \\
\hline Satisfaction with health & 0.016 & $(0.024)$ & $0.072^{* * * *}$ & $(0.027)$ \\
\hline Current health: good & -0.019 & $(0.118)$ & 0.155 & $(0.123)$ \\
\hline Current health: satisfactory & 0.245 & $(0.141)$ & $0.412 * * *$ & $(0.148)$ \\
\hline Current health: poor & $0.564 * * *$ & $(0.186)$ & $0.574 * * *$ & $(0.190)$ \\
\hline Current health: bad & 0.251 & $(0.318)$ & 0.361 & $(0.355)$ \\
\hline Strong worries about job security & -0.056 & $(0.104)$ & -0.061 & $(0.119)$ \\
\hline
\end{tabular}




\begin{tabular}{|c|c|c|c|c|}
\hline \multirow{3}{*}{$\begin{array}{l}\text { Estimation strategy } \\
\text { Some worries about job security }\end{array}$} & \multicolumn{2}{|c|}{ OLS } & \multicolumn{2}{|c|}{ FE } \\
\hline & \multicolumn{2}{|c|}{ (2) } & \multicolumn{2}{|c|}{ (4) } \\
\hline & $-0.195 * * *$ & $(0.072)$ & -0.032 & $(0.074)$ \\
\hline Regional unemployment rate & $0.071 * * *$ & $(0.010)$ & -0.015 & $(0.029)$ \\
\hline Industry dummies & \multicolumn{2}{|c|}{ Yes } & \multicolumn{2}{|c|}{ Yes } \\
\hline Firm size dummies & \multicolumn{2}{|c|}{ Yes } & \multicolumn{2}{|c|}{ No } \\
\hline Time dummies & \multicolumn{2}{|c|}{ Yes } & \multicolumn{2}{|c|}{ Yes } \\
\hline Occupation dummies & \multicolumn{2}{|c|}{ Yes } & \multicolumn{2}{|c|}{ Yes } \\
\hline Firm spell fixed effects & \multicolumn{2}{|c|}{ No } & \multicolumn{2}{|c|}{ Yes } \\
\hline$R^{2} / R^{2}$-within & \multicolumn{2}{|c|}{0.305} & \multicolumn{2}{|c|}{0.102} \\
\hline$N$ & \multicolumn{2}{|c|}{30,699} & \multicolumn{2}{|c|}{31,522} \\
\hline
\end{tabular}

Note: $* p<0.1 ; * * p<0.05$; *** $p<0.01$. The dependent variable is $\Delta W H$. The values in parentheses represent robust standard errors clustered at the individual level. The reference group for the working time regimes is 'fixed working time' (FWT). The reference group for the job autonomy dummies is 'low autonomy'. The reference group for the dummies representing current health is 'very good'. The reference group for the dummies representing worries about job security is 'no worries'. Number of industry dummies: 9/10. Number of firm size dummies: 3/4. Number of time dummies: 4/5. Number of occupation dummies: 1288/1289. Number of worker-firm spell fixed effects: 14,321 . 


\section{S3. Description of the variables}

Table S5: Definition and descriptive statistics of the variables

\begin{tabular}{|c|c|c|c|c|c|}
\hline Variable & Definition & $N$ & Mean & Std & Min-Max \\
\hline \multicolumn{6}{|l|}{ Dependent variable } \\
\hline$\Delta W H$ & $\begin{array}{l}\text { Difference between average actual and contractual } \\
\text { working time per week }\end{array}$ & 38,312 & 3.68 & 5.44 & $-38-42$ \\
\hline \multicolumn{6}{|c|}{ Main explanatory variables } \\
\hline $\begin{array}{l}\text { Self-managed } \\
\text { working time } \\
(S M)\end{array}$ & $\begin{array}{l}\text { Dummy variable indicating whether or not an employee } \\
\text { has extensive decision-making authority in terms of } \\
\text { scheduling individual working hours (reference group: } \\
\text { fixed working time) }\end{array}$ & 38,312 & 0.11 & 0.31 & $0-1$ \\
\hline $\begin{array}{l}\text { Employer- } \\
\text { determined } \\
\text { working time } \\
(E D)\end{array}$ & $\begin{array}{l}\text { Dummy variable indicating whether or not an employee } \\
\text { faces flexible working hours determined by the } \\
\text { employer (reference group: fixed working time) }\end{array}$ & 38,312 & 0.22 & 0.41 & $0-1$ \\
\hline $\begin{array}{l}\text { Flexitime within a } \\
\text { working hours } \\
\text { account }(F T)\end{array}$ & $\begin{array}{l}\text { Dummy variable indicating whether or not an employee } \\
\text { is allowed to vary daily working hours, where daily } \\
\text { attendance is restricted to a defined time interval } \\
\text { (working hours account) (reference group: fixed } \\
\text { working time) }\end{array}$ & 38,312 & 0.22 & 0.41 & $0-1$ \\
\hline $\begin{array}{l}\text { Positive } \\
\text { reciprocity }(R)\end{array}$ & See footnote 18 & 34,877 & 0.41 & 0.49 & $0-1$ \\
\hline $\begin{array}{l}\text { Intrinsic } \\
\text { motivation ( } I M)\end{array}$ & $\begin{array}{l}\text { Dummy variable indicating whether an employee's } \\
\text { desired working time per week } \geq \text { the contractual } \\
\text { working time per week }\end{array}$ & 37,809 & 0.74 & 0.44 & 0.1 \\
\hline $\begin{array}{l}\text { Performance } \\
\text { evaluation }(P E)\end{array}$ & $\begin{array}{l}\text { Dummy variable indicating whether or not an } \\
\text { employee's performance is regularly evaluated by a } \\
\text { supervisor }\end{array}$ & 33,645 & 0.31 & 0.46 & $0-1$ \\
\hline $\begin{array}{l}\text { Performance } \\
\text { evaluation } \\
\text { without } \\
\text { consequences } \\
\left(P E_{1}\right)\end{array}$ & $\begin{array}{l}\text { Dummy variable indicating whether or not an } \\
\text { employee's performance is regularly evaluated by a } \\
\text { supervisor without involving consequences for monthly } \\
\text { gross salary, yearly bonus payments, future salary } \\
\text { increases, or potential promotions }\end{array}$ & 33,645 & 0.11 & 0.31 & $0-1$ \\
\hline $\begin{array}{l}\text { Performance } \\
\text { evaluation with } \\
\text { consequences } \\
\left(P E_{2}\right)\end{array}$ & $\begin{array}{l}\text { Dummy variable indicating whether or not an } \\
\text { employee's performance is regularly evaluated by a } \\
\text { supervisor with consequences for monthly gross salary, } \\
\text { yearly bonus payments, future salary increases, or } \\
\text { potential promotions }\end{array}$ & 33,645 & 0.2 & 0.4 & $0-1$ \\
\hline \multicolumn{6}{|l|}{ Control variables } \\
\hline $\begin{array}{l}\text { Low job } \\
\text { autonomy }\end{array}$ & $\begin{array}{l}\text { Dummy variable indicating mainly manual workers } \\
\text { with a low level of status and a low level of autonomy }\end{array}$ & 38,312 & 0.16 & 0.36 & $0-1$ \\
\hline $\begin{array}{l}\text { Low / medium job } \\
\text { autonomy }\end{array}$ & $\begin{array}{l}\text { Dummy variable indicating workers in production and } \\
\text { services demanding a minimal level of specialization, } \\
\text { and farm workers. }\end{array}$ & 38,312 & 0.3 & 0.46 & $0-1$ \\
\hline
\end{tabular}




\begin{tabular}{|c|c|c|c|c|c|}
\hline Variable & Definition & $N$ & Mean & Std & Min-Max \\
\hline $\begin{array}{l}\text { Medium job } \\
\text { autonomy }\end{array}$ & $\begin{array}{l}\text { Dummy variable indicating jobs that require completion } \\
\text { of the middle track of secondary education and entail a } \\
\text { limited amount of responsibility }\end{array}$ & 38,312 & 0.33 & 0.47 & $0-1$ \\
\hline $\begin{array}{l}\text { Medium / high } \\
\text { job autonomy }\end{array}$ & $\begin{array}{l}\text { Dummy variable indicating jobs carried out either with } \\
\text { or without supervision that require a degree from a } \\
\text { college of applied sciences or university, but are not } \\
\text { very high in prestige }\end{array}$ & 38,312 & 0.19 & 0.4 & $0-1$ \\
\hline $\begin{array}{l}\text { High job } \\
\text { autonomy }\end{array}$ & $\begin{array}{l}\text { Dummy variable indicating managers and freelance } \\
\text { academics }\end{array}$ & 38,312 & 0.02 & 0.13 & $0-1$ \\
\hline $\begin{array}{l}\text { Monthly gross } \\
\text { wage }\end{array}$ & $\begin{array}{l}\text { Gross wage of the employee in the month before the } \\
\text { survey (in 1,000 Euros) }\end{array}$ & 38,312 & 2.42 & 1.6 & $0.40-30.0$ \\
\hline Job satisfaction & $\begin{array}{l}\text { Ordinal variable ranging from } 0 \text { to } 10 \text {, indicating an } \\
\text { employee's job satisfaction ( } 0 \text { : completely unsatisfied, } \\
\text { 10: completely satisfied) }\end{array}$ & 37,822 & 6.95 & 1.99 & $0-10$ \\
\hline $\begin{array}{l}\text { Satisfaction with } \\
\text { household income }\end{array}$ & $\begin{array}{l}\text { Ordinal variable ranging from } 0 \text { to } 10 \text {, indicating an } \\
\text { employee's satisfaction with household income ( } 0 \text { : } \\
\text { completely unsatisfied, 10: completely satisfied) }\end{array}$ & 38,000 & 6.4 & 2.09 & $0-10$ \\
\hline $\begin{array}{l}\text { Living with } \\
\text { partner }\end{array}$ & $\begin{array}{l}\text { Dummy variable indicating whether or not an employee } \\
\text { has a settled living partner }\end{array}$ & 38,116 & 0.84 & 0.36 & $0-1$ \\
\hline $\begin{array}{l}\text { Children aged } \\
\text { under } 16\end{array}$ & $\begin{array}{l}\text { Dummy variable indicating whether or not an employee } \\
\text { has one or more children aged under } 16 \text { who currently } \\
\text { live in the household }\end{array}$ & 38,276 & 0.36 & 0.48 & $0-1$ \\
\hline $\begin{array}{l}\text { Full-time } \\
\text { employed }\end{array}$ & $\begin{array}{l}\text { Dummy variable indicating whether or not an employee } \\
\text { is employed full-time }\end{array}$ & 36,133 & 0.77 & 0.42 & $0-1$ \\
\hline $\begin{array}{l}\text { Fixed-term } \\
\text { contract }\end{array}$ & $\begin{array}{l}\text { Dummy variable indicating whether or not an employee } \\
\text { has a fixed-term contract }\end{array}$ & 36,827 & 0.09 & 0.29 & $0-1$ \\
\hline Employer change & $\begin{array}{l}\text { Dummy variable indicating whether or not an employee } \\
\text { realised an employer change in the year before the } \\
\text { survey }\end{array}$ & 38,312 & 0.08 & 0.27 & $0-1$ \\
\hline Male & $\begin{array}{l}\text { Dummy variable indicating whether or not an employee } \\
\text { is male }\end{array}$ & 38,312 & 0.5 & 0.5 & $0-1$ \\
\hline $\begin{array}{l}\text { Foreign } \\
\text { nationality }\end{array}$ & $\begin{array}{l}\text { Dummy variable indicating whether or not an employee } \\
\text { is of non-German nationality }\end{array}$ & 38,312 & 0.07 & 0.26 & $0-1$ \\
\hline Job tenure & Years of an employee's job tenure & 38,267 & 10.75 & 9.65 & $0-50.9$ \\
\hline Schooling & Years of schooling an employee has had & 37,278 & 12.39 & 2.53 & $7-18$ \\
\hline $\begin{array}{l}\text { Full-time } \\
\text { experience }\end{array}$ & Years of an employee's experience in a full-time job & 37,972 & 15.82 & 11.26 & $0-49$ \\
\hline $\begin{array}{l}\text { Part-time } \\
\text { experience }\end{array}$ & Years of an employee's experience in a part-time job & 37,972 & 2.93 & 5.45 & $0-45$ \\
\hline $\begin{array}{l}\text { Unemployment } \\
\text { experience }\end{array}$ & Years of a worker's unemployment experience & 37,972 & 0.61 & 1.55 & $0-24.1$ \\
\hline $\begin{array}{l}\text { Hobbies and other } \\
\text { leisure activities }\end{array}$ & $\begin{array}{l}\text { Number of hours devoted to hobbies and other leisure } \\
\text { activities on a typical working day }\end{array}$ & 37,104 & 1.59 & 1.36 & $0-15$ \\
\hline
\end{tabular}




\begin{tabular}{|c|c|c|c|c|c|}
\hline Variable & Definition & $N$ & Mean & Std & Min-Max \\
\hline $\begin{array}{l}\text { Satisfaction with } \\
\text { health }\end{array}$ & $\begin{array}{l}\text { Ordinal variable ranging from } 0 \text { to } 10 \text { that indicates the } \\
\text { degree of satisfaction with an employee's health }(0 \text { : } \\
\text { completely unsatisfied, } 10 \text { : completely satisfied) }\end{array}$ & 38,246 & 6.92 & 1.98 & $0-10$ \\
\hline $\begin{array}{l}\text { Current health: } \\
\text { good }\end{array}$ & $\begin{array}{l}\text { Dummy variable indicating whether or not an employee } \\
\text { assesses his current health status as good (reference } \\
\text { group: very good) }\end{array}$ & 38,254 & 0.48 & 0.5 & $0-1$ \\
\hline $\begin{array}{l}\text { Current health: } \\
\text { satisfactory }\end{array}$ & $\begin{array}{l}\text { Dummy variable indicating whether or not an employee } \\
\text { assesses his current health status as satisfactory } \\
\text { (reference group: very good) }\end{array}$ & 38,254 & 0.32 & 0.47 & $0-1$ \\
\hline $\begin{array}{l}\text { Current health: } \\
\text { poor }\end{array}$ & $\begin{array}{l}\text { Dummy variable indicating whether or not an employee } \\
\text { assesses his current health status as poor (reference } \\
\text { group: very good) }\end{array}$ & 38,254 & 0.1 & 0.3 & $0-1$ \\
\hline $\begin{array}{l}\text { Current health: } \\
\text { bad }\end{array}$ & $\begin{array}{l}\text { Dummy variable indicating whether or not an employee } \\
\text { assesses his current health status as bad (reference } \\
\text { group: very good) }\end{array}$ & 38,254 & 0.01 & 0.11 & $0-1$ \\
\hline $\begin{array}{l}\text { Strong worries } \\
\text { about job security }\end{array}$ & $\begin{array}{l}\text { Dummy variable indicating whether or not an employee } \\
\text { is strongly concerned about his job security (reference } \\
\text { group: no worries) }\end{array}$ & 37,435 & 0.16 & 0.37 & $0-1$ \\
\hline $\begin{array}{l}\text { Some worries } \\
\text { about job security }\end{array}$ & $\begin{array}{l}\text { Dummy variable indicating whether or not an employee } \\
\text { is somewhat concerned about his job security (reference } \\
\text { group: no worries) }\end{array}$ & 37,435 & 0.44 & 0.5 & $0-1$ \\
\hline Firm size $20-200$ & $\begin{array}{l}\text { Dummy variable indicating whether or not an employee } \\
\text { works in a firm that employs between } 20 \text { and } 200 \\
\text { employees (reference group: <20) }\end{array}$ & 37,259 & 0.3 & 0.46 & $0-1$ \\
\hline $\begin{array}{l}\text { Firm size 201- } \\
2000\end{array}$ & $\begin{array}{l}\text { Dummy variable indicating whether or not an employee } \\
\text { works in a firm that employs between } 201 \text { and } 2000 \\
\text { employees (reference group: <20) }\end{array}$ & 37,259 & 0.23 & 0.42 & $0-1$ \\
\hline Firm size $>2000$ & $\begin{array}{l}\text { Dummy variable indicating whether or not an employee } \\
\text { works in a firm that employs more than } 2000 \text { employees } \\
\text { (reference group: <20) }\end{array}$ & 37,259 & 0.23 & 0.42 & $0-1$ \\
\hline $\begin{array}{l}\text { Regional } \\
\text { unemployment } \\
\text { rate }\end{array}$ & $\begin{array}{l}\text { Average unemployment rate of the German federal } \\
\text { state, where the employee lives }(\%)\end{array}$ & 38,276 & 10.8 & 4.51 & $4.3-22.1$ \\
\hline \multicolumn{6}{|c|}{ Alternative measures of extra work } \\
\hline $\begin{array}{l}\text { Overtime last } \\
\text { month }\end{array}$ & $\begin{array}{l}\text { Number of overtime hours an employee has executed in } \\
\text { the recent month before the survey }\end{array}$ & 37,467 & 2.26 & 3.55 & $0-22.8$ \\
\hline$\Delta W H_{2}$ & $\begin{array}{l}\text { Difference between the number of working hours in a } \\
\text { typical week (including commuting times as well as } \\
\text { working hours devoted to a potential second job, as well } \\
\text { as work at Saturdays and Sundays) and the weekly } \\
\text { contractual working hours }\end{array}$ & 35,541 & 10.48 & 9.42 & $-59.5-108$ \\
\hline \multicolumn{6}{|c|}{ Alternative productivity measures } \\
\hline Absenteeism & Number of annual days absent from work due to illness & 32,096 & 8.41 & 21.95 & $0-365$ \\
\hline $\begin{array}{l}\text { Worries about job } \\
\text { security }\end{array}$ & $\begin{array}{l}\text { Ordinal variable ranging between } 1 \text { and } 3 \text { indicating } \\
\text { strong / some / no worries about job security }\end{array}$ & 37,435 & 2.23 & 0.71 & $1-3$ \\
\hline
\end{tabular}




\begin{tabular}{|c|c|c|c|c|c|}
\hline Variable & Definition & $N$ & Mean & Std & Min-Max \\
\hline Hourly wage & $\begin{array}{l}\text { Gross monthly wage of the employee divided by actual } \\
\text { monthly working hours (in Euros) }\end{array}$ & 38,312 & 14.63 & 8.83 & $1.5-263.7$ \\
\hline Task efficiency & $\begin{array}{l}\text { Dummy variable indicating whether or not an employee } \\
\text { approves to the statement: "I see myself as someone who } \\
\text { does things effectively and efficiently" (original variable } \\
\text { is ordinal ranging between 1: does not apply to me at all } \\
\text { and 7: applies to me perfectly; threshold: 6) }\end{array}$ & 15,522 & 0.73 & 0.45 & $0-1$ \\
\hline \multicolumn{6}{|c|}{ Non-standard working hours } \\
\hline $\begin{array}{l}\text { Work in the } \\
\text { evening }\end{array}$ & $\begin{array}{l}\text { Dummy variable indicating whether or not an employee } \\
\text { at least occasionally works in the evening }\end{array}$ & 29,241 & 0.51 & 0.5 & $0-1$ \\
\hline Work at night & $\begin{array}{l}\text { Dummy variable indicating whether or not an employee } \\
\text { at least occasionally works at night }\end{array}$ & 28,188 & 0.26 & 0.44 & $0-1$ \\
\hline Work on Saturday & $\begin{array}{l}\text { Dummy variable indicating whether or not an employee } \\
\text { at least occasionally works on Saturdays }\end{array}$ & 29,364 & 0.6 & 0.49 & $0-1$ \\
\hline Work on Sunday & $\begin{array}{l}\text { Dummy variable indicating whether or not an employee } \\
\text { at least occasionally works on Sundays }\end{array}$ & 28,263 & 0.34 & 0.47 & $0-1$ \\
\hline \multicolumn{6}{|c|}{ Indicators related to intrinsic motivation } \\
\hline Job satisfaction & $\begin{array}{l}\text { Ordinal variable ranging from } 0 \text { to } 10 \text {, indicating an } \\
\text { employee's job satisfaction ( } 0 \text { : completely unsatisfied, } \\
\text { 10: completely satisfied) }\end{array}$ & 56,339 & 6.97 & 1.95 & $0-10$ \\
\hline Sacrifice & $\begin{array}{l}\text { Dummy variable indicating whether or not an employee } \\
\text { approves to the statement: "Those closest to me say I } \\
\text { sacrifice myself too much for my job" (original variable } \\
\text { is ordinal ranging between } 1 \text { : strongly disagree and } 4 \text { : } \\
\text { strongly agree; threshold: } 3 \text { ) }\end{array}$ & 12,109 & 0.4 & 0.49 & $0-1$ \\
\hline Unpaid overtime & $\begin{array}{l}\text { Percentage of unpaid overtime work in the month before } \\
\text { the survey }\end{array}$ & 30,339 & 0.2 & 0.39 & $0-1$ \\
\hline Hard-working & $\begin{array}{l}\text { Dummy variable indicating whether or not an employee } \\
\text { approves to the statement: "I see myself as someone who } \\
\text { tends to be lazy" (reversed; original variable is ordinal } \\
\text { ranging between 1: does not apply to me at all and 7: } \\
\text { applies to me perfectly; threshold: 2) }\end{array}$ & 12,425 & 0.89 & 0.31 & $0-1$ \\
\hline Thorough & $\begin{array}{l}\text { Dummy variable indicating whether or not an employee } \\
\text { approves to the statement: "I see myself as someone who } \\
\text { does a thorough job" (original variable is ordinal } \\
\text { ranging between 1: does not apply to me at all and } 7 \text { : } \\
\text { applies to me perfectly; threshold: } 6 \text { ) }\end{array}$ & 12,444 & 0.86 & 0.35 & $0-1$ \\
\hline Task efficiency & $\begin{array}{l}\text { Dummy variable indicating whether or not an employee } \\
\text { approves to the statement: "I see myself as someone who } \\
\text { does things effectively and efficiently" (original variable } \\
\text { is ordinal ranging between 1: does not apply to me at all } \\
\text { and 7: applies to me perfectly; threshold: 6) }\end{array}$ & 12,433 & 0.73 & 0.44 & $0-1$ \\
\hline
\end{tabular}




\begin{tabular}{|c|c|c|c|c|c|}
\hline Variable & Definition & $N$ & Mean & Std & Min-Max \\
\hline Joy at work & $\begin{array}{l}\text { Dummy variable indicating whether or not an employee } \\
\text { approves to the statement: "I do not really enjoy my } \\
\text { work" (original variable is ordinal ranging between } 1 \text { : } \\
\text { applies to me perfectly and } 4 \text { : does not apply to me at } \\
\text { all; threshold: } 3 \text { ) }\end{array}$ & 6,072 & 0.84 & 0.37 & $0-1$ \\
\hline \multicolumn{6}{|c|}{ Work load indicators } \\
\hline Work strain & $\begin{array}{l}\text { Dummy variable indicating whether or not an employee } \\
\text { approves to the statement: "The amount of work has } \\
\text { increased steadily over the last two years" }\end{array}$ & 12,073 & 0.65 & 0.48 & $0-1$ \\
\hline Time pressure & $\begin{array}{l}\text { Dummy variable indicating whether or not an employee } \\
\text { approves to the statement : "Because of the high volume } \\
\text { of work there is often high time pressure" }\end{array}$ & 12,139 & 0.64 & 0.48 & $0-1$ \\
\hline \multicolumn{6}{|c|}{ Indicators for extrinsic motivation } \\
\hline Paid overtime & $\begin{array}{l}\text { Percentage of paid overtime work in the month before } \\
\text { the survey }\end{array}$ & 30,339 & 0.8 & 0.39 & $0-1$ \\
\hline $\begin{array}{l}\text { Expected } \\
\text { promotion }\end{array}$ & $\begin{array}{l}\text { Self-reported probability of receiving a promotion at the } \\
\text { current place of employment }\end{array}$ & 25,764 & 0.29 & 0.45 & $0-1$ \\
\hline Expected pay rise & $\begin{array}{l}\text { Self-reported probability of receiving an individual pay } \\
\text { rise that goes beyond the collectively negotiated pay } \\
\text { rate increase }\end{array}$ & 25,761 & 0.26 & 0.44 & $0-1$ \\
\hline \multicolumn{6}{|c|}{ Exclusion restrictions } \\
\hline$S M_{t-2}$ & Two years lagged observations of $S M$ & 23,192 & 0.11 & 0.31 & $0-1$ \\
\hline$E D_{-2}$ & Two years lagged observations of $E D$ & 23,192 & 0.21 & 0.41 & $0-1$ \\
\hline$F T_{t-2}$ & Two years lagged observations of $F T$ & 23,192 & 0.23 & 0.42 & $0-1$ \\
\hline $\begin{array}{l}\text { Group-specific } \\
\text { mean for } \\
\text { employees with } \\
\text { SMWT }\end{array}$ & $\begin{array}{l}\text { Average share of } S M \text { in groups separated by } 2 \\
\text { occupational status classes, } 4 \text { firm size classes, } 10 \\
\text { industry classes, } 16 \text { regional classes, and } 5 \text { time periods }\end{array}$ & 36,480 & 0.12 & 0.25 & $0-1$ \\
\hline
\end{tabular}

Note: $N$ is the number of observations. Std is standard deviation. In order to save space the information for 1289 occupation dummies, 10 industry dummies, and five time dummies are not displayed.

\section{References}

Baltagi, B.H., 2008. Econometric Analysis of Panel Data, 4th ed. Chichester, UK: John Wiley \& Sons.

Fernandez-Val, I., Vella, F., 2011. Bias corrections for two-step fixed effects panel data estimators. Journal of Econometrics 163, 144-162.

Greene, W.H., 2008. Econometric Analysis, 6th ed. New Jersey: Pearson. 
Vella, F., Verbeek, M., 1998. Whose wages do unions raise? A dynamic model of unionism and wage rate determination for young men. Journal of Applied Econometrics 13, 163-183.

Woessmann, L., West, M., 2006. Class-size effects in school systems around the world: evidence from between-grade variation in TIMSS. European Economic Review 50, 695-736. 